\title{
Música para la mano izquierda: un camino hacia la documentación de su repertorio pianístico en Latinoamérica
}

\author{
Music for the left hand: a path towards \\ the documentation of its piano repertoire \\ in Latin America
}

\author{
por \\ Leonardo Gell Fernández-Cueto \\ Universidad de Costa Rica, Costa Rica \\ leonardo.gell_f@ucr.ac.cr
}

\begin{abstract}
Documentar y difundir la música latinoamericana sigue siendo un desafío que enfrentamos como región. Si bien existen esfuerzos importantes en varios países, donde estudios, publicaciones y grabaciones de este repertorio aumentan, el camino es aún incipiente frente a la cantidad de material existente. En esta dirección, el presente artículo se propone realizar un primer registro de la música concebida para la ejecución del piano con solo la mano izquierda, a partir del interés que han mostrado creadores latinoamericanos por este tipo de obras. Las tablas confeccionadas incluyen el registro de partituras originales y transcripciones de obras de otros autores, escritas entre 1859 y 2019, al tiempo que valida la hipótesis de que Costa Rica es el país latinoamericano con mayor cantidad de obras para mano izquierda. Además, se basa en las fuentes existentes para exponer las características de ejecución de esta literatura pianística surgida en Europa a finales del siglo XVIII, y realiza un repaso por el comportamiento que ha tenido a lo largo de más de dos siglos.

Palabras claves: música latinoamericana, piano, mano izquierda, pedagogía musical, didáctica instrumental.

Documenting and spreading Latin American music continues to be a challenge that we still face as a region today. Although there are important efforts in several countries, where studies, publications and recordings of this repertoire continue to grow, we can consider that it is still at an initial stage. Given this fact, this article aims to register, for the first time, music conceived for piano with the left hand only, based on the interest shown by Latin American composers for this kind of work. The tables elaborated include the recording of original works and the transcriptions of works by other authors, written between 1859 and 2019. It also validates the hypothesis that Costa Rica is the Latin American country with the highest number of works written for the left hand. Based on existing sources, it shows the characteristics of the execution for this piano literature that emerged in Europe at the end of the 18th century and reviews the development it has had over two centuries.
\end{abstract}

Keywords: Latin American music, piano, left hand, musical pedagogy, instrumental teaching. 


\section{INTRODUCCIÓN}

La inclusión de música latinoamericana en los programas de estudio de los conservatorios y universidades de la región goza de un interés creciente por parte de quienes reconocen su importancia en la formación académica de las nuevas generaciones, pues muchas veces su difusión recae en eventos e instituciones que a nivel profesional propician un espacio para ella. El conocimiento de este repertorio depende en gran medida de la voluntad de investigadores y centros de estudio que lo documenten y publiquen, con el propósito de ponerlo al alcance de todos.

Latinoamérica, por ser una región diversa, enfrenta varios retos en esta dirección: primero, el aprendizaje formal en centros educativos se enfoca casi exclusivamente a instrumentos europeos heredados y no necesariamente se interactúa con aquellos pertenecientes a las comunidades autóctonas de cada país; segundo, reconocer la diversidad cultural de la región mediante la inclusión de elementos folclóricos en las obras; y tercero, dar a conocer ese legado propio a una comunidad musical que rebasa las fronteras nacionales desde donde se gesta el ejercicio creativo.

Son muchos los esfuerzos que se realizan en diferentes países por estudiar, publicar o registrar en soportes audiovisuales la producción latinoamericana, con el propósito de saldar esa deuda con nuestra música. Sin embargo, queda un largo camino por recorrer, especialmente con repertorios menos favorecidos, como es el caso del concebido para la ejecución del piano solo con la mano izquierda. Este corpus específico cuenta con miles de obras producidas, fundamentalmente en Europa, Norteamérica y Australia, gran parte de ellas registradas en publicaciones formales.

Entre los referentes principales se encuentran los libros Piano Music for One Hand (1994) de Theodore Edel y One Handed: A Guide to Piano Music for One Hand (1999) de Donald Patterson (De Araujo 2009: 6). Este último es más exhaustivo que el anterior por el volumen de obras registradas para la mano izquierda, la propuesta de organización desde los niveles pedagógicos hasta el repertorio de concierto y la discusión que realiza en torno a las dificultades de ejecución (Wiley 2000: 377) ${ }^{1}$. Un panorama más actualizado lo encontramos en la página web creada por Hans Brofeldt, quien por más de treinta años ha conseguido documentar la labor de más de ochocientos compositores en todo el mundo, interesados en escribir para la mano izquierda sola ${ }^{2}$. Brofeldt asegura que su trabajo también supera la información aportada por Edel, teniendo en cuenta que desde la publicación de aquel texto continúan aumentado los registros en su sitio en línea ${ }^{3}$.

Sin embargo, aún no se han encontrado publicaciones dedicadas exclusivamente a documentar el repertorio para mano izquierda en la región latinoamericana, lo que justifica la pertinencia de este artículo. Si bien los textos de Edel y Patterson incluyen algunas obras de compositores latinoamericanos, estas constituyen un porcentaje ínfimo respecto del corpus expuesto de otras regiones del mundo. Por ello, nuestro objetivo general se centrará en registrar las obras latinoamericanas, con el propósito de iniciar un camino

1 En McRoberts (2000) pueden encontrarse otros comentarios acerca del libro de Patterson.

2 El sitio, denominado Piano Music for the Left Hand Alone, puede visitarse en http://www.lefthand-brofeldt.dk/index.htm. Fue develado para esta investigación por Carmen Méndez, mediante una comunicación personal con el autor el 27 de febrero de 2019.

3 Ver en http://www.left-hand-brofeldt.dk/index.htm. No obstante, la información que ofrece Brofeldt acerca de cada obra y compositor no es completa, por cuanto quedan lagunas en algunos casos acerca del año de composición, posibles publicaciones en partitura y otros datos de interés. En ese sentido, los libros de Edel y Patterson, aunque no contienen un número tan extenso de registros en comparación a Brofeldt, muestran un trabajo sistematizado en la información que proporcionan. 
que pueda enriquecerse con el aporte futuro de otros colegas interesados en el tema. A partir de este, nos planteamos dos objetivos específicos: comparar el aporte de cada país al repertorio latinoamericano para la mano izquierda y determinar las condiciones que dieron lugar a que en Costa Rica se concibieran obras pianísticas con estas características, país desde donde se realiza esta investigación.

\section{METODOLOGÍA}

Las fuentes consultadas permitieron organizar el artículo de la siguiente manera: primero se exponen las características de ejecución de las obras para mano izquierda, y luego se realiza un repaso por el contexto histórico en el que se produjo el repertorio canónico para esta mano en solitario. Posteriormente, se presentan cuatro tablas, de propia elaboración, que registran la mayor cantidad posible de obras dedicadas a la mano izquierda en Latinoamérica: la primera, con obras para piano solo; la segunda, con obras para grupos de cámara; la tercera, con obras para piano y orquesta; y la cuarta, con la única obra encontrada para piano y otro medio. Cada base de datos bibliográfica incluye la siguiente información: nombre del compositor (organizado por orden alfabético), años de nacimiento y muerte (en casos de compositores fallecidos), país, título de la obra, año de composición, publicación o revisión (según aplique), formato instrumental (en la Tabla 2) y la(s) fuente(s) de la(s) que se extrajeron dichos datos ${ }^{4}$.

Para ello se realizó una búsqueda en repositorios digitales, páginas web de compositores y editoriales, programas de mano y crónicas de conciertos, grabaciones discográficas, así como investigaciones publicadas en artículos, libros y tesis. Con el propósito de complementar la información extraída de estas fuentes, se recurrió a la comunicación directa con varios creadores, investigadores y pianistas especializados en repertorio latinoamericano.

La información colectada en las tablas ofrecerá la posibilidad de establecer criterios comparativos de la producción individual de cada país de la región, como pueden ser: cantidad de obras, partituras originales y transcripciones, formatos preferidos (piano solo, conjuntos de cámara y conciertos con acompañamiento orquestal), número de compositores y compositoras y siglo en el que fueron creadas las obras. Sostenemos la hipótesis de que Costa Rica es el país latinoamericano con mayor número de obras pianísticas dedicadas a la mano izquierda, por lo que hacia el final del artículo se comentarán las condiciones que propiciaron la concepción de este corpus, específicamente tras la publicación del libro Metodología para la enseñanza del piano para solo la mano izquierda (2016) de Pilar Aguilar.

Motivado por Aguilar, el autor de este artículo se acercó por primera vez al repertorio pianístico para mano izquierda, lo que derivó en el estreno de varias obras costarricenses entre 2014 y 2017, algunas de ellas registradas en producciones discográficas. Este acercamiento desde la interpretación fue el punto de partida para abordar la presente investigación. Se espera que la publicación del artículo sirva de apoyo a un proyecto de docencia, donde estudiantes de la Universidad de Costa Rica interpreten parte de la literatura latinoamericana para mano izquierda. De esta forma, el trabajo directo con las partituras se complementará con los resultados de la investigación, concretando así

4 Las fuentes expuestas en las Tablas 1, 2 y 3 aportaron la información que se expone acerca de cada obra. El propósito que se persigue con su inclusión en la última columna de cada tabla es el de visibilizar cuáles son los investigadores o sitios en internet que han citado o estudiado a profundidad el repertorio objeto de estudio. En la lista de referencias, al final del artículo, podrán obtenerse más detalles de las fuentes en cuestión. 
un proceso que involucra varias aristas en torno a la música: composición, investigación, docencia e interpretación.

\section{CARACTERÍSTICAS DE EJECUCIÓN DE LA MÚSICA PARA MANO IZQUIERDA}

Varios estudios acerca del repertorio para mano izquierda exponen las razones por las que ha sido más común el uso de esta extremidad respecto de su homóloga en el hemisferio derecho. Una de ellas es la aparición del pedal de resonancia en el piano moderno (siglo XVIII), que permite mantener la sonoridad a lo largo de todas las tesituras del instrumento. Esto ofrece la posibilidad de crear la "ilusión sonora de que el intérprete está tocando en varias zonas del teclado al mismo tiempo con las dos manos, cuando solo hay una" (Moro 2007: 29). A ello debe añadirse el empleo del pedal tonal (ubicado en el centro de los tres pedales del piano), mediante este puede prolongarse el sonido de las notas en el registro grave, mientras el ejecutante activa con libertad el pedal derecho (o de resonancia).

Más allá de estas posibilidades mecánicas del piano, existe un componente anatómico que brinda al intérprete un mejor acomodo en una obra escrita para mano izquierda, respecto de la derecha. Por su posición frente al registro grave, la izquierda es la más apropiada para trabajar con esta sección sonora, si consideramos, además, que la música tonal establece su construcción armónica partiendo del bajo (sonido más grave de un acorde). Por el contrario, si la obra estuviese escrita para la mano derecha, el pianista se vería obligado a realizar movimientos más grandes con el torso de su cuerpo para trasladarse de un registro a otro. Esto, sin olvidar que la resonancia que se consigue con la tesitura grave del instrumento es mayor a la que emana de los registros central y agudo.

Sandra Wing-Yee afirma que en estos casos no se trata de utilizar el cuerpo como trípode (considerando en su conjunto a las dos manos y el torso como apoyo a estas), sino que el torso debe inclinarse un poco más hacia adelante para apoyar a la mano con la que se ejecuta en solitario. Con el movimiento del cuerpo en función del desplazamiento de la mano izquierda sobre el teclado, puede ofrecérsele el soporte necesario para evitar un mayor esfuerzo (Citada en Patterson 1999: 8). Paul Wittgenstein, por su parte, recomienda sentarse ligeramente hacia el lado derecho de la banqueta del instrumento, con el dedo meñique sobre el do central, pues esto permitirá un alcance mayor respecto del registro agudo del teclado (Patterson 1999: 8).

Minji Lee toma como referentes algunos diseños pianísticos para ofrecer consejos acerca de los movimientos de la muñeca, como pueden ser: rotatorios, horizontales o verticales. Sus propuestas también toman en consideración la participación del antebrazo y el hombro para lograr una relajación adecuada. Asimismo, sugiere un grupo de soluciones interpretativas a partir de ejemplos concretos en pasajes de las partituras canónicas: digitaciones específicas, ligeros cambios de agógica y uso del pedal de resonancia (Lee 2017, pp. 18-28).

Para Daniel Moro, Leopold Godowsky (1870-1938) fue uno de los principales defensores del rol que jugaba esta extremidad en la ejecución del piano, ya que su dedo pulgar es el "más fuerte de ambas manos y ... el más indicado para ejecutar una melodía cantabile de forma expresiva e intensa" (Moro 2007: 29). Efectivamente, el trabajo con la mano izquierda sola contribuye a mejorar su agilidad y desplazamiento, pero también a optimizar su flexibilidad y capacidad para cantar con solo cinco dedos. Se trata de delegar en una mano las tareas que comúnmente son asumidas por ambas, incluso, en tejidos polifónicos, que hasta el momento se abordaban casi exclusivamente en obras de Johann Sebastian Bach (1685-1750), por ejemplo. 
Por medio de un simple análisis anatómico, y teniendo en cuenta determinados diseños pianísticos, es más cómodo para el intérprete destacar una línea melódica superior con el pulgar y dejar al resto de los dedos la tarea de ejecutar un material armónico de relleno a la misma. Moro añade que:

Este diseño musical, repetidísimo durante el Clasicismo y en muchos casos en el Romanticismo, se adecúa mejor a la mano izquierda debido a que la melodía ha de destacarse por encima de todo, con el pulgar como el dedo más fuerte de ambas manos, y los demás dedos, más débiles, realizan el acompañamiento con menor intensidad sonora (Moro 2007: 31).

El autor se refiere a la utilización de la textura homofónica en las partituras instrumentales, que se debía en gran medida al auge de la ópera y el bel canto, dominantes en el gusto del público y de muchos compositores a partir del siglo XVIII. Patterson se apega a este planteamiento, ya que en las obras para ambas manos, generalmente, la melodía recae en los dedos más débiles de la derecha (cuarto y quinto), mientras que el pulgar, siendo el más fuerte de todos, está destinado a tocar ideas de sonoridad secundaria respecto de la melodía. Por el contrario, cuando esto sucede en la mano izquierda sola se invierten los patrones tradicionales, en tanto el pulgar tiene la responsabilidad de ejecutar la melodía superior de una obra (Patterson 1999: 9).

En el período decimonónico comenzó a revolucionarse la mecánica instrumental y, por esta razón, la técnica de ejecución alcanzó un punto culminante. Para entonces, muchos pianistas-compositores, como fue el caso de Franz Liszt (1811-1886), decidieron explotar al máximo el desempeño de ambas manos, exigiéndole a la izquierda despojarse de su zona de comodidad. Como se verá más adelante, para ese momento comenzaron a surgir algunos ejercicios y estudios enfocados en desarrollar las habilidades de ejecución de la mano izquierda, en tanto práctica consciente de su rezago respecto de la derecha. Estas evoluciones en la ejecución y la técnica instrumental tienen su génesis en los avances tecnológicos. Por consiguiente, si el piano moderno disponía de otros mecanismos expresivos (como sus tres pedales), las obras escritas para él debían explotar todas sus capacidades sonoras y, de esta forma, la literatura para mano izquierda se vio beneficiada.

No es objetivo de esta investigación referirse a la totalidad del repertorio para mano izquierda, pues ha sido documentado mayoritariamente en las publicaciones de Edel, Patterson y Brofeldt. No obstante, se considera importante dedicar el siguiente apartado a repasar parcialmente el corpus creado entre los siglos XVIII y XX, de manera que el lector obtenga información relacionada con las principales motivaciones que dieron lugar a su aparición y auge, así como a las funciones que ha tenido a lo largo de varios siglos.

\section{REPERTORIO CANÓNICO PARA MANO IZQUIERDA}

Los orígenes del repertorio para la mano izquierda sola nos remiten al Divertimento (1770) del compositor alemán Carl Philipp Emanuel Bach (1714-1788) ${ }^{5}$. Quizás fue el hijo de Johann Sebastian Bach el primero en interesarse por un mejor desempeño de este miembro corporal. A esta partitura le sucedieron varios tratados y compendios de estudios técnicos, enfocados directamente en explotar las habilidades motrices de la mano izquierda.

5 De Araujo asegura que esta obra es comúnmente conocida como Solfeggieto, aunque su denominación original es Clavierstück für die rechte oder linke hand allein. Además, agrega que su creación se estima entre 1770 y 1771 (2009: 9). 
El austriaco Carl Czerny (1791-1857), importante creador de ejercicios didácticos para el piano, compuso su Opus 735 (publicado por Wessel \& Co, en 1846) especialmente para la mano izquierda. Otro de los primeros fue el alemán Johann Hermann Berens (18261880) con El cultivo de la mano izquierda op. 89 (1872), que incluye cuarenta y seis ejercicios y veinticinco estudios. Asimismo, el francés Camille Saint-Saëns (1835-1921) escribió sus Seis Estudios op. 135 (1912) en forma de danzas para la mano izquierda (Preludio, Alla Fuga, Moto Perpetuo, Bourée, Elégie y Gigue); mientras que el suizo Emile Robert Blanchet (18771943) incluyó algunos ejercicios técnicos con el mismo fin, en su colección de Preludios op. 41 (1925). Por su parte, el austriaco Paul Wittgenstein (1887-1961) dedicó el segundo volumen de The School For The Left Hand (publicado por Universal Edition, en 1957) a trece estudios destinados a diferentes dificultades: para la técnica de una línea individual, para los pasajes de notas dobles y para la técnica polifónica (Moro 2007, pp. 34-35) ${ }^{6}$.

Otros compositores también dedicaron parte de su actividad creativa a escribir estudios pianísticos solo para la mano izquierda, como fueron: Felix Blumenfeld (1863-1931), Max Reger (1873-1916), Béla Bartók (1881-1945) (Nieto 1991, pp. 17-20), Ferdinando Bonamici (1827-1905), Moritz Moszkowski (1854-1925), Josef Hoffmann (1870-1956), Thérèse Brenet (n. 1935) y John Corigliano (n. 1938) (Moro 2007, pp. 34-35). A esta lista debemos sumar a Godowsky, quien fuese apodado como "el Apóstol de la mano izquierda" (Nieto 1991: 12). Godowsky concibió un extenso catálogo de transcripciones a partir de obras originales, fundamentalmente del siglo XIX, donde resaltan las realizadas a los famosos Estudios op. 10 y op. 25 de Fryderyk Chopin (1810-1849), "consideradas como uno de los mayores logros en el campo de la transcripción musical" (Moro 2007: 29).

Junto con esta literatura enfocada en el aspecto motriz de la mano izquierda, fueron muy populares las transcripciones de arias de óperas y paráfrasis que contenían los temas principales de esas obras escénicas o de canciones concebidas originalmente para voz y piano. Su propósito era, en alguna medida, demostrar que los pianistas podían ejecutarlas con una sola mano, en este caso, aquella que normalmente requería un mayor esfuerzo por su poca participación en el repertorio a dos manos. Un ejemplo lo encontramos en el pianista y compositor italiano Adolfo Fumagalli (1828-1856), quien viajó por Europa interpretando música de salón y media docena de paráfrasis de óperas escritas para la mano izquierda sola (Edel 1994: 21).

Precisamente, Helder de Araujo señala que en la primera mitad del siglo XIX la música para mano izquierda se convirtió en objeto de atracción, como algo curioso a nivel visual, aspecto que fue explotado por los pianistas de la época durante sus apariciones públicas (De Araujo 2009: 11). El primero que actuó frente a una audiencia tocando solo con la mano izquierda fue el checo Alexander Dreyschock (1818-1869), quien llamó la atención de Felix Mendelssohn-Bartholdy (1809-1847) por su alto virtuosismo con esa extremidad (Edel 1994: 17). Contrario a Dreyschock y Fumagalli, que se acercaron al repertorio para mano izquierda aun cuando contaban con sus dos brazos, el húngaro Geza Zichy (1849-1924) fue el primer pianista sin brazo derecho en dedicar recitales íntegramente al repertorio para la mano izquierda, además de haber compuesto el primer concierto para piano y orquesta, donde el solista solo utiliza la zurda (Lee 2017: 9).

La curiosidad suscitada por esta práctica llevó a algunos creadores a incluir al piano en ensambles de diversa índole, donde era ejecutado con la mano izquierda, otro aspecto llamativo que diversificó las propuestas musicales de la época. Además, durante el siglo XX fue concebida una cantidad importante de conciertos para piano y orquesta. Esto supuso

${ }^{6}$ La mayoría de las fechas de composición o publicación en partituras pertenecen a una búsqueda propia, ya que la fuente citada no incluye esta información en todos los casos. 
llevar a un nivel más alto de exhibicionismo el desempeño de los pianistas que los interpretaban, bien por placer o por alguna necesidad física.

La aparición de las obras concertantes se debe en gran medida al pianista austriaco Paul Wittgenstein, quien perdió su brazo derecho en la Primera Guerra Mundial. Wittgenstein, inspirado en Zichy, se convirtió en el segundo pianista dedicado únicamente al repertorio para mano izquierda (Lee 2017: 9). Su gran aporte fue la comisión de varios conciertos para piano y orquesta a los principales compositores de su tiempo, ofreciéndoles a cambio "una cantidad de dinero que desconocemos" (Acebo 2017: párr. 3). Fue así como vieron la luz obras de Richard Strauss (1864-1949), Karl Wiegl (1881-1949), Serguei Prokofiev (1891-1953), Paul Hindemith (1895-1963), Maurice Ravel (1875-1937), Erich Wolfgang Korngold (1897-1957) y Benjamin Britten (1913-1976) 7 .

Blake Howe asegura que Wittgenstein violó la narrativa ideológica del desempeño musical al transgredir los límites del cuerpo del intérprete para encarnar no solo la inefabilidad de la música, sino también la agilidad, destreza y habilidad sobrehumanas que exige su desempeño físico (Howe 2010: 136). Esta afirmación nos lleva a pensar en el gran esfuerzo físico que demanda la interpretación de una obra con acompañamiento sinfónico, máxime si esta fue compuesta en el siglo XX. Para entonces, las orquestaciones alcanzaron un número de músicos antes insospechado, por lo que el desempeño del solista debía apelar a habilidades técnicas que se ajustaran al lenguaje moderno y conseguir una mayor cantidad de sonido. Al respecto, Albert Nieto nos dice:

Wittgenstein se quejó de que los Estudios Sinfónicos que Richard Strauss escribiera para él emplearan un acompañamiento orquestal con demasiados instrumentos de viento, y no poder luchar contra ellos solo con su mano izquierda: "con todo, no puedo decirle a Strauss que su orquesta no es la que se requiere...", se lamentaba el pianista (Nieto 1991: 13).

Otro ejemplo lo encontramos en la respuesta que le dio Wittgenstein a Prokofiev, en 1930, luego de haberle enviado la partitura de su cuarto concierto para piano y orquesta: "Le doy las gracias por su concierto, pero no entiendo ni una sola nota del mismo y no voy a interpretarlo" (Nieto 1991, pp. 13-14). Lo cierto es que Wittgenstein no llegó a estrenar algunos de los conciertos que había comisionado, pues no siempre se identificaba con la estética creativa de su tiempo. Algunos textos que narran la vida de este pianista dan testimonio de sus discusiones con Ravel acerca de su concierto para la mano izquierda y que, además, impidió a otros colegas estudiar las partituras comisionadas por él, alegando que aún se encontraban dentro del período pactado con el compositor para el uso de la obra ${ }^{8}$.

Otros pianistas con afectaciones en su brazo derecho fueron responsables de la aparición de obras importantes en el repertorio:

Otakar Hollmann ... pidió a Martinu y a Janacek que le escribieran música para su mano válida, surgiendo el Concierto para piano n. 4 y el Capriccio para piano y siete instrumentos, respectivamente. [Mientras] ... Montigny-Rémaury fue la causa de que Saint-Saens compusiera los Seis estudios Op. 135, y de que el pianista-compositor Cor de Groot escribiera sus Apparitions (Nieto 1991: 14).

Acebo agrega que Hollmann (1894-1967) se inspiró en Wittgenstein y "decidió completar [sus] estudios de piano, aprendiendo las técnicas creadas por este” (Acebo 2017:

7 De Araujo asegura que fueron casi cuarenta las obras que se concibieron para Wittgenstein, incluidos diecisiete conciertos para piano y orquesta, de estos, no todos han sido editados (2009: 24).

8 Varios detalles acerca de esto se ofrecen en Nieto (1991: 13), Edel (1994: 32), De Araujo (2009, pp. 24-26), Lee (2017: 10) y Acebo (2017). 
párr. 11). A diferencia de Wittgenstein, Hollmann no poseía los recursos económicos suficientes para pagar la comisión de obras, por lo que acudió a la buena voluntad de compositores checos y eslovacos conocidos por él, como los citados anteriormente, pero también de Josef Bohuslav Foerster (1859-1951), Josef Bartovsky (1884-1964), Vincenc Stastny (1885-1971), Václav Kaprál (1889-1947), Erwin Schulhoff (1894-1942), Jaroslav Tomášek (1896-1970), Jaroslav Řídký (1897-1956), Aleš Jermář (1929-2004) y Stanko Rajčić (s/d) (Acebo 2017: párr. 12) ${ }^{9}$.

Comisionar obras a compositores contemporáneos ha sido una praxis recurrente hasta nuestros días. Nieto, tras "haber sufrido esporádicamente una lesión en la mano derecha", unido al interés por estudiar y difundir la música nueva, le llevó a encargar obras para mano izquierda a catorce compositores españoles hacia finales del siglo XX, dando como resultado un compendio de igual número de partituras (Nieto 1991: 21) ${ }^{10}$.

En Estados Unidos, por ejemplo, incrementaron las publicaciones en partituras de obras con una sola mano a partir de las décadas de 1870 y 1880, debido a la oleada de soldados que perdieron algún miembro superior durante la Guerra Civil (Lerner 2006: 76). Neil Lerner comenta aspectos relevantes a varias producciones de Warner Brothers, compañía que a lo largo del siglo XX llevó al cine historias relacionadas con personas mutiladas y en las que se incluyeron obras para la mano izquierda sola. En su texto, la autora hace referencia también al impacto que tienen en la audiencia las formas de tratar estas discapacidades, específicamente el caso de las manos incorpóreas. Según Lerner, se da un fenómeno de transición entre la monstruosidad que genera el cuerpo mutilado y su posterior normalización, incluso, de cara a la posible amenaza para el cuerpo simbólico de la música clásica, con sus mensajes implícitos de forma perfecta y ejecución perfecta (Lerner 2006: 86).

Como pudo apreciarse anteriormente, la popularidad alcanzada por la literatura para mano izquierda se debió también a intérpretes que han decidido abordarlo, aun cuando no presentan ninguna discapacidad en el brazo derecho, lo que:

supone un gran gesto de humildad: el reto de renunciar a la gama sonora y a las posibilidades técnicas que ofrece la unión de ambas manos en virtud de la elección de un camino difícil, la búsqueda del máximo nivel técnico y musical... con solo una mano (Moro 2007: 29).

Quizás esto se deba a que, en medio de una competitividad cada vez más árida, los pianistas que dedican parte de su quehacer a dicho repertorio encuentran en este la posibilidad de ofrecer al público una propuesta diferente, escasamente explotada por los ejecutantes que marcan los estándares más altos del gremio a nivel internacional, lo que puede considerarse un acierto. Se ha dado el caso de algunos compositores que han escrito para la mano derecha sola, quizás, como un ejercicio contestatario o en contraposición a la enorme literatura dedicada a la mano izquierda a lo largo de la historia. Tal es el caso del cubano Juan Piñera (n. 1949) con su obra Diurno y Postludio (1994), precisamente, como respuesta al op. 9 (1894) del ruso Alexander Scriabin (1872-1915), compuesto por un Nocturno y un Preludio (De la Hoz 2006: párr. 10, Castañeda 2015: párr. 6); aunque estas no son las únicas páginas que Piñera ha dedicado a la mano derecha en solitario. Obras

9 La mayoría de los años de nacimiento y muerte responden a una búsqueda propia, ya que la fuente citada no aporta dicha información.

10 La interpretación de este corpus fue realizada por Nieto en Madrid, el 20 de marzo de 1991, recital en el que tuvo su estreno mundial la mayoría de obras (ver Nieto 1991, pp. 10-11). 
similares de otros autores pueden encontrarse en los textos de Edel y Patterson, aunque no se trata de un compendio tan extenso como el de la mano izquierda sola ${ }^{11}$.

\section{REPERTORIO LATINOAMERICANO PARA MANO IZQUIERDA}

Malgré Tout (1900) del mexicano Manuel Ponce (1882-1948) es quizás la obra latinoamericana más antigua que se conoce comúnmente entre los pianistas ${ }^{12}$. Sin embargo, esta investigación arrojó que existen piezas anteriores, siendo los registros más antiguos: Vals de Salón, op. 62 (1859) del puertorriqueño Manuel Gregorio Tavarez (1843-1883) ${ }^{13}$ y Home Sweet Home (Chanson anglaise transcripte pour le piano), op. 91 (1872) del chileno Federico Guzmán (1836-1885) ${ }^{14}$.

$\mathrm{Al}$ igual que ha sucedido con el repertorio para ambas manos en nuestra región, la música original para mano izquierda no ha estado exenta de alegorías a danzas decimonónicas del viejo continente, que recurren al estilo romántico aun cuando fueran concebidas en la primera mitad del siglo XX. Basados en la función social que tuvo la música en su momento, en algunos países latinoamericanos hemos empleado para ellas el término "música de salón"15. Podemos citar, por ejemplo: Polca (compuesta entre las décadas de 1910 y 1920) del brasileño Ernesto Nazareth (1863-1934), Mazurka (1917) del colombiano Gonzalo Vidal (1863-1946) y el mencionado Vals de Salón, op. 62 de Tavarez. Otros compositores han recurrido a denominaciones comunes como: preludio, intermezzo, nocturno, toccata, impromptu o elegía, que forman parte de una tradición extendida -a la usanza europea- en nuestros países, incluso adentrado el siglo XXI.

De igual manera encontramos un gran número de estudios, entre ellos: Sete Estudos em Forma de Suíte Antiga (1921) del brasileño Paulo Florence (1864-1949), Three Etudes (1984/1985/2005) del argentino Raoul Sosa (n. 1939), Seis Estudios (1996) de la brasileña Monique Aragão (n. 1960), Dos Estudios (2014) del costarricense José Mora-Jiménez (n. 1977) y casi setenta de estas piezas agrupadas en los Opus 186, 249 y 251 del también

11 Patterson afirma que el $80 \%$ del repertorio para una mano está destinado a la izquierda, entre otras causas, debido a las continuas lesiones de los pianistas en la mano derecha, por ser la más explotada. No obstante, añade que las obras para mano derecha sola suenan como si no tuviesen fundamento, pues falta la sonoridad de anclaje en el registro grave que ofrezca apoyo al oyente desde la base (1999: 10).

12 Ver https://www.ecured.cu/Manuel_Mar\%C3\%ADa_Ponce [acceso: 25 de noviembre de 2020]

13 Patterson afirma que la obra fue "compuesta alrededor de 1859" (1999: 163). La traducción del inglés es propia. Esta es la única fuente a la que se ha tenido acceso, que ofrece información acerca del año de composición.

14 Ver http://pianolatinoamerica.org/e_guzman/e_guzmanintro.html [acceso: 25 de noviembre de 2020] El año de nacimiento de Federico Guzmán fue corregido durante la revisión de este artículo, pues muchas fuentes muestran erróneamente esta información como 1827, cuando en realidad se trata de 1836. Neil Lerner asegura que la canción Home, Sweet Home (1823), original de John Howard Payne (1791-1852, letra) y Henry Bishop (1787-1856, música), fue una de las melodías populares más utilizadas en transcripciones para la mano izquierda, entre las décadas de 1870 y 1880 , como fue el caso del compositor James Welhi (2006: 87). Este dato coincide con el año en que el chileno Guzmán realizó su transcripción (1872).

15 Según María Clara Vargas: "El término ‘música de salón’ fue acuñado por Robert Schumann, en 1838, para diferenciar la producción musical de entretenimiento de la producción de música de cámara de origen más bien alemán. La primera era una música liviana, generalmente compuesta por piezas cortas que acompañaban las tertulias, los bailes o las confidencias. El denominador común de este tipo de repertorio era un acuerdo tácito con una moda cuyo referente fundamental era Francia" (2004: 166). 
costarricense Mario Alfagüell (n. 1948). Entre los conciertos y sonatas -partituras con mayores proporciones artísticas- hallamos: Conciertos nos. 5 y $6(1979 / 1987)$ del argentino Juan Carlos Biondi (n. 1933), Concerto with string orchestra (1989) de Sosa, Piano Concerto for Left Hand (2001) del puertorriqueño Luis Prado (n. 1968), Concertino para mano izquierda y orquesta op. 26 (2011) del venezolano Gerardo Gerulewicz (n. 1966) y varias sonatas y sonatinas para piano o dúo con piano de Sosa, Alfagüell, el chileno Mario Gómez Vignes (n. 1934) y el brasileño Artur Cimirro (n. 1982).

Una mención especial merecen aquellas transcripciones de obras originalmente europeas, algunas con el propósito de utilizarse en un momento temprano de la formación instrumental, mientras que otras persiguen ese atractivo del pasado por llevar a la mano izquierda partituras muy conocidas del repertorio canónico. El volumen mayor de estas versiones lo han aportado Sosa, Cimirro y los costarricenses Pilar Aguilar (n. 1956) e Ismael Gamboa (n. 1992). Acerca de su versión de la famosa pieza El vuelo del moscardón (1899-1900) de Nikólai Rimsky-Korsakov (1844-1908), Cimirro asegura que es "más difícil que la de György Cziffra, con muchas terceras, quintas y octavas"16. Este testimonio nos lleva a pensar en una partitura de inmenso reto virtuosístico para la mano izquierda sola, ya que la versión realizada por Cziffra destaca por la alternancia de acordes y octavas entre ambas manos.

Otros títulos sugieren también un interés por recrear ritmos autóctonos de los países de origen, lo que constituye un aporte al folclor nacional, a saber: Dieciocho variaciones clásicas pampeanas (1942) de la argentina Elsa Calcagno (1910-1978); Payadoresco (1970), uno de los Cinco Preludios Nacionales del argentino Ángel Lasala (1914-2000); Pequeño Son (1972) de la cubana María Enma Botet (1903-1989); y el pasillo Febrero, op. 369 (2014) de la costarricense Ana Isabel Vargas (n. 1949). Algo interesante que se ha dado también en Latinoamérica, aunque en menor medida, es la aparición de obras camerísticas, donde el piano se ejecuta únicamente con la mano izquierda. Tal es el caso de Sosa, Alfagüell, Gamboa, el mexicano Antonio Gomezanda (1894-1961) y el uruguayo Miguel del Águila (n. 1957), quienes han explorado las combinaciones del dúo con piano, alternándolo con el violín, la viola, el violonchelo, la flauta, el fagot o la voz. Ello permite ampliar el desempeño profesional de un pianista que carece de su brazo derecho, más allá de las posibilidades que brinda el repertorio en solitario.

El 14 de diciembre de 2019 concluyó la confección de las tablas que se ofrecerán a continuación. Su información es el resultado de una búsqueda en repositorios digitales, páginas web de compositores y editoriales, programas de mano y crónicas de conciertos, grabaciones discográficas, tesis académicas, así como publicaciones en artículos y libros. Además, se acudió a la comunicación electrónica con varios creadores -o sus colaboradores-, investigadores y pianistas especializados en repertorio latinoamericano, con la intención de complementar los datos obtenidos de las fuentes antes mencionadas. Fue así como brindaron su aporte: Alexis Aranda (México), Andrés Posada (Colombia), Alessandra Feris, Artur Cimirro (Brasil), Alberto Joya, Ernesto Oliva (Cuba), Carmen Méndez, Ismael Gamboa, Manuel Matarrita (Costa Rica), Krysia Samán (Venezuela/Costa Rica), Miguel del Águila y Gustavo Britos (Uruguay) ${ }^{17}$.

Ante la inexistencia de un catálogo específico de música latinoamericana para mano izquierda, nos proponemos aquí iniciar ese camino, de manera que sea documentado

16 Traducción propia, a partir de sus declaraciones al sitio de Brofeldt. Disponible en: http:// www.left-hand-brofeldt.dk/Catalogue_c.htm

17 Otros colegas mostraron su interés por aportar a la investigación, aunque la información ofrecida coincidía con resultados ya obtenidos durante el proceso de búsqueda. A todos ellos se agradece el tiempo invertido. 
este corpus y aumenten sus registros en el futuro a partir de investigaciones similares. Consideramos que ese es el principal aporte del artículo. Las tablas abarcan partituras escritas entre 1859 y 2019. Fueron organizadas teniendo en cuenta el orden alfabético de los compositores (de acuerdo con el primer apellido). En el caso de quienes han escrito varias obras, se decidió ordenarlas por año de composición, desde la más antigua hasta la más reciente. Por tanto, quedan hacia el final aquellas que no tienen este dato, ya que algunas fuentes no pudieron aportar esta información. Las obras cíclicas, como grupos de estudios, piezas o preludios fueron incluidas con el nombre global u opus que le dio su autor, sin hacer mención de cada una de sus partes integrantes, como tampoco a los movimientos internos de sonatas y conciertos para piano y orquesta.

Algunos compositores no nacieron en países latinoamericanos, pero han desarrollado la mayor parte de su vida y labor creativa en ellos. Se trata de Tsuna Iwami (Japón/Brasil), Akiana Molina (Bélgica/Costa Rica) y Carlos Escalante (España/Costa Rica). En el caso de Mario Gómez Vignes, aunque su obra para mano izquierda forma parte de una antología pedagógica colombiana y vive hace varias décadas en ese país, se optó por indicar su origen chileno, por tratarse igualmente de un país latinoamericano. Varias abreviaturas podrán observarse en las tres tablas, las que aclaramos a continuación (ver Tablas 1, 2 y 3):

ed.: indica que el año pertenece a la edición en partitura y no al año de composición, en los casos en los cuales no ha podido obtenerse esa información.

rev.: se refiere al año reciente de revisión de la partitura, cuando este difiere del año de composición.

s/d: alude a aquellas obras de las cuales no pudo hallarse su año de composición o edición en partitura.

Para cumplir con el primer objetivo específico de esta investigación, se expondrá varios datos cuantitativos por país, considerando la elaboración de la Tabla 4 como el instrumento más apropiado para representarla. En ella se incluyeron varios aspectos, que citaremos a continuación con su respectivo acrónimo o abreviatura: cantidad de obras aportada por cada país (Ob.), número de compositores (Comp.), cuántos de ellos son hombres $(\mathrm{H})$ o mujeres (M), siglo en el que fueron concebidas las obras (S. XIX, S. XX, S. XXI), aquellas que quedaron sin fechar $(\mathrm{s} / \mathrm{f})$, cuántas son partituras originales (Or.) o transcripciones (Transc.) y cantidad de obras dedicadas a formatos en solitario (Pno.), camerístico (Gr.), que requieren acompañamiento orquestal $(\mathrm{C} / \mathrm{O})$ o para piano y otro medio (POM).

La información colectada incluye doscientos veintiún registros de obras producidas en Latinoamérica para la mano izquierda, provenientes de once países (ver Figura 1) y concebidas por cincuenta y dos compositores y diez compositoras. Entre las partituras, dos fueron escritas en el siglo XIX, sesenta en el XX y ciento cincuenta y dos entre 2000 y diciembre de 201918; mientras que siete han quedado sin fechar (ver Figura 2). No obstante, la tendencia ubica a la presente centuria como la más prolífica.

18 Raoul Sosa compuso tres estudios para piano, los dos primeros en 1984 y 1985, respectivamente; mientras que el tercero fue escrito en 2005. Por ello, fueron contabilizados en la Tabla 4 según el siglo, aunque tienen un único registro en la Tabla 1, por considerarse un ciclo de tres obras. 


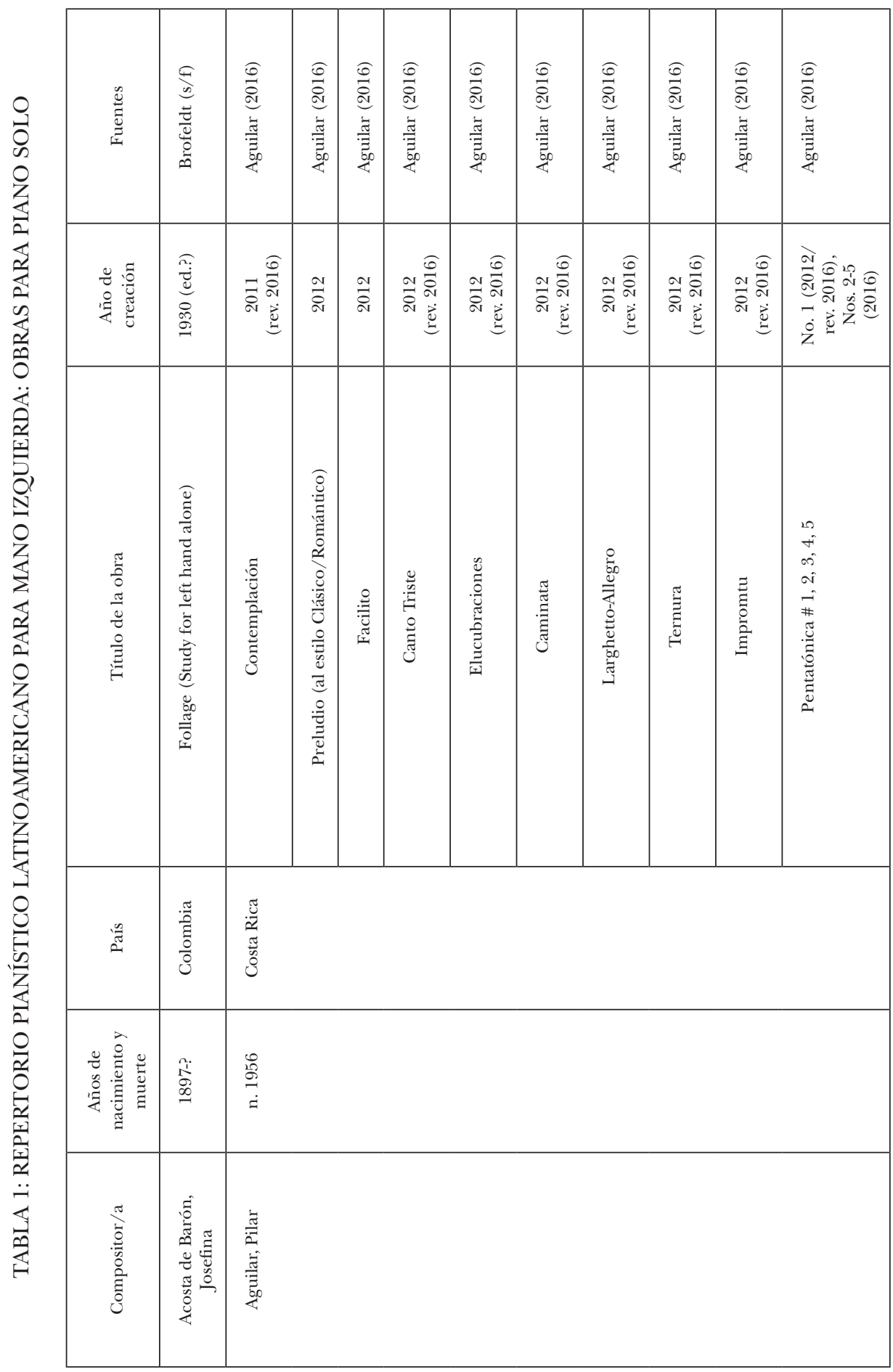




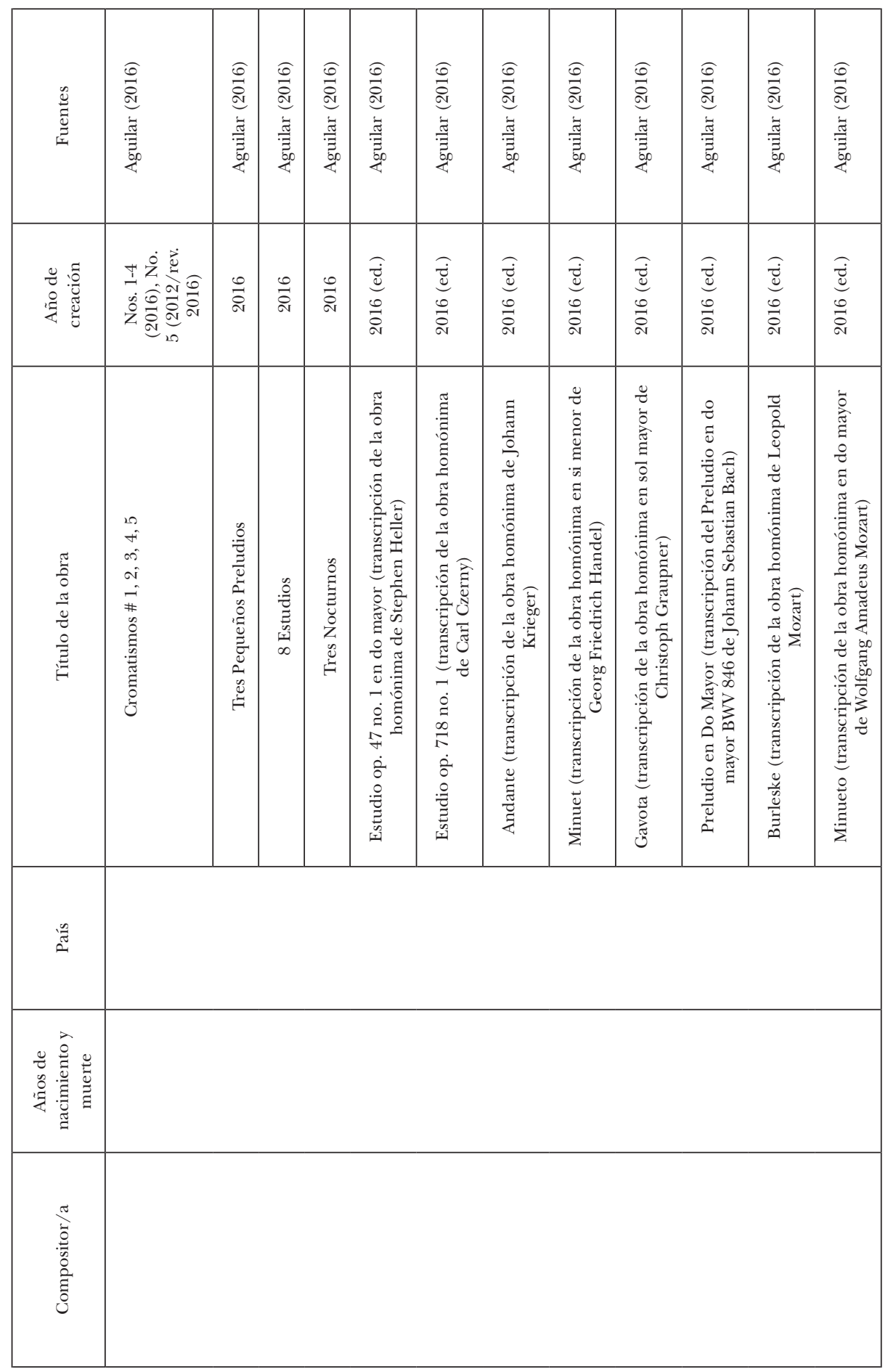




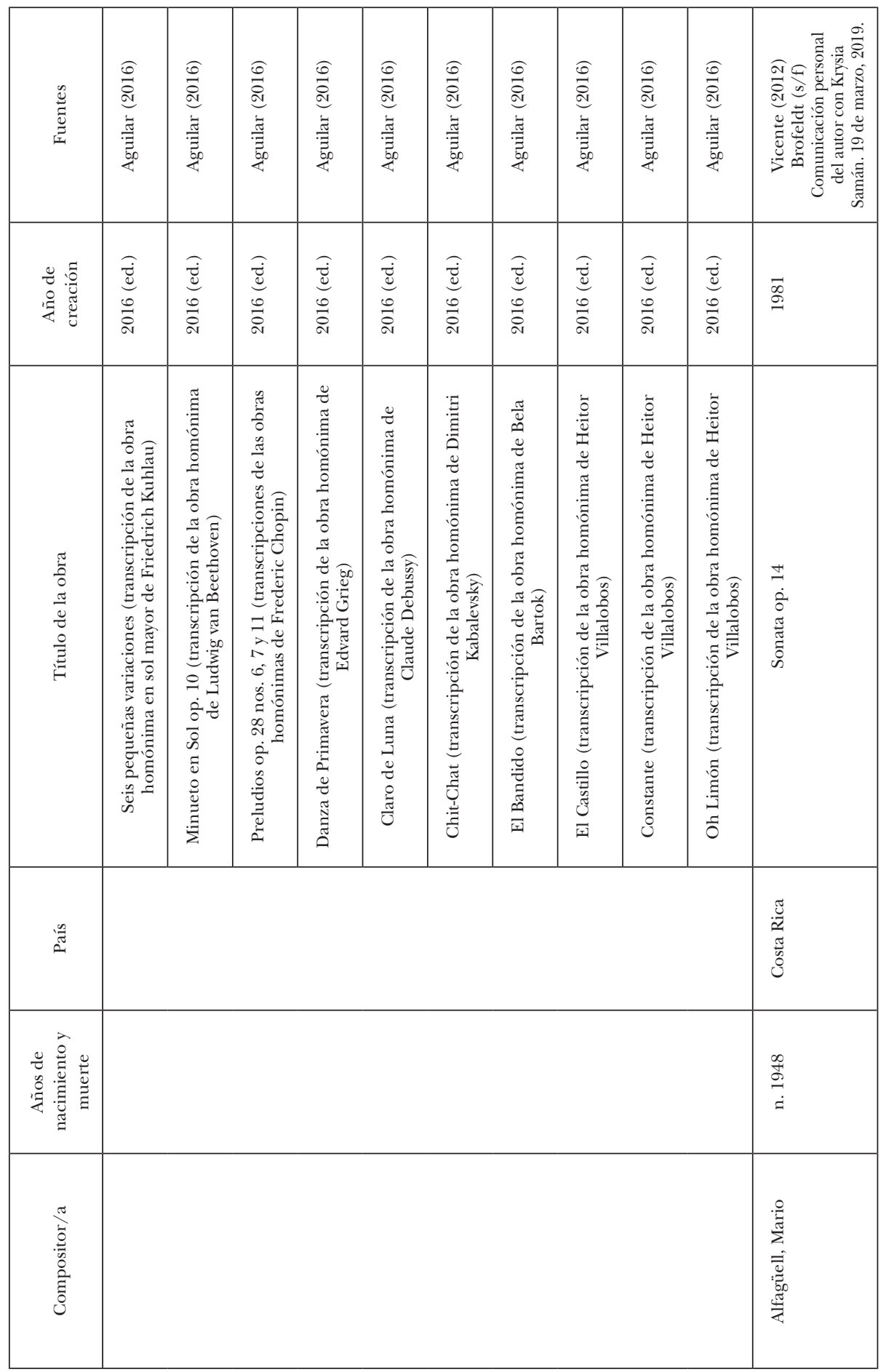




\begin{tabular}{|c|c|c|c|c|c|c|}
\hline 总 & 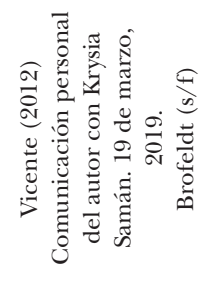 & 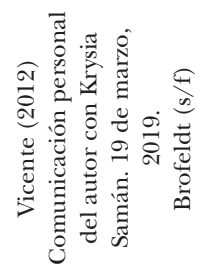 & 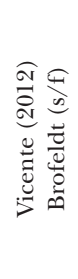 & 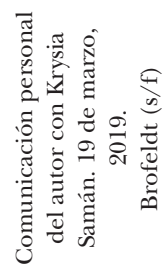 & 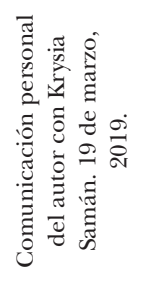 & 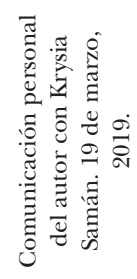 \\
\hline 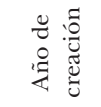 & $\stackrel{\vec{\infty}}{\stackrel{\sigma}{\sigma}}$ & 呑 & 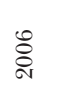 & 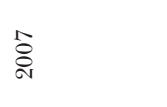 & $\begin{array}{l}\text { \&े } \\
\text { ণे }\end{array}$ & $\overrightarrow{\text { จे }}$ \\
\hline $\begin{array}{l}\frac{\pi}{0} \\
\frac{0}{0} \\
\frac{\pi}{0} \\
\frac{\pi}{0} \\
0 \\
\frac{0}{3} \\
0\end{array}$ & 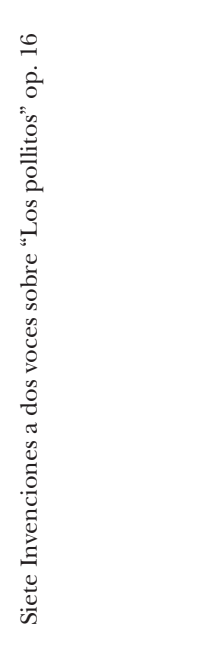 & $\begin{array}{l}f \\
\dot{0} \\
\dot{0} \\
\frac{\pi}{\pi} \\
\tilde{0} \\
\dot{0}\end{array}$ & 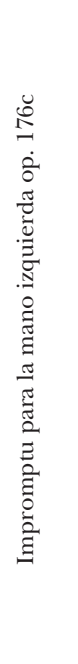 & 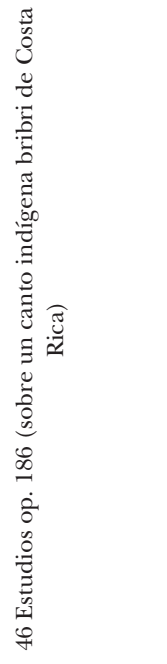 & 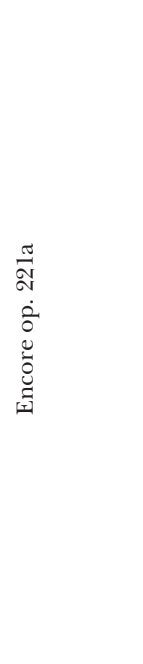 & 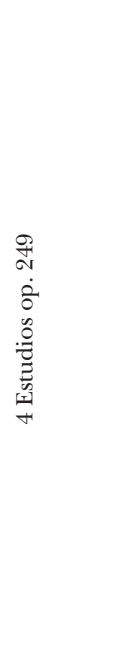 \\
\hline$\frac{n}{\tilde{\omega}}$ & & & & & & \\
\hline 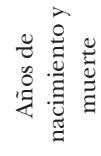 & & & & & & \\
\hline 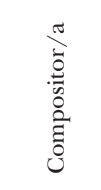 & & & & & & \\
\hline
\end{tabular}




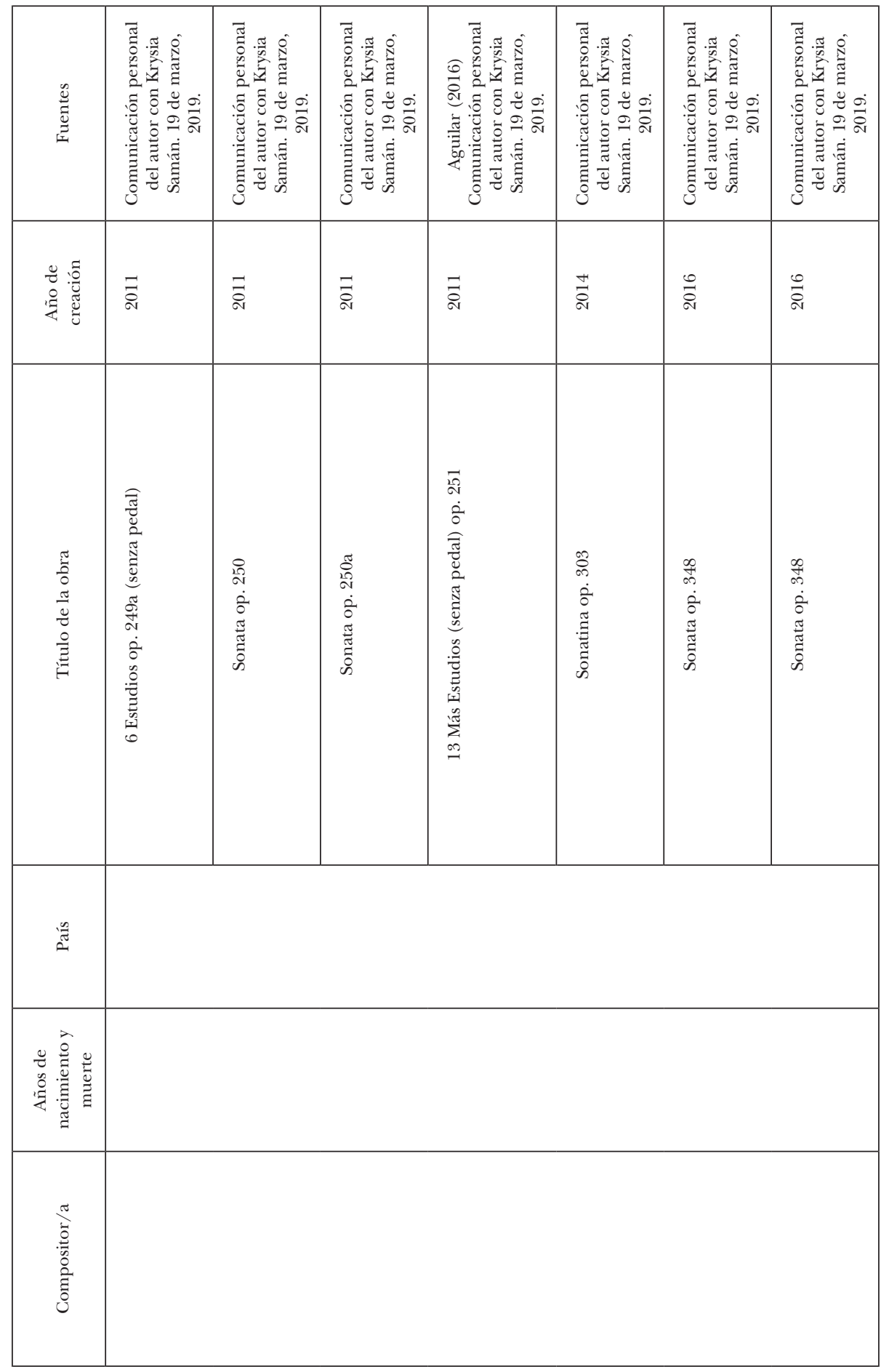




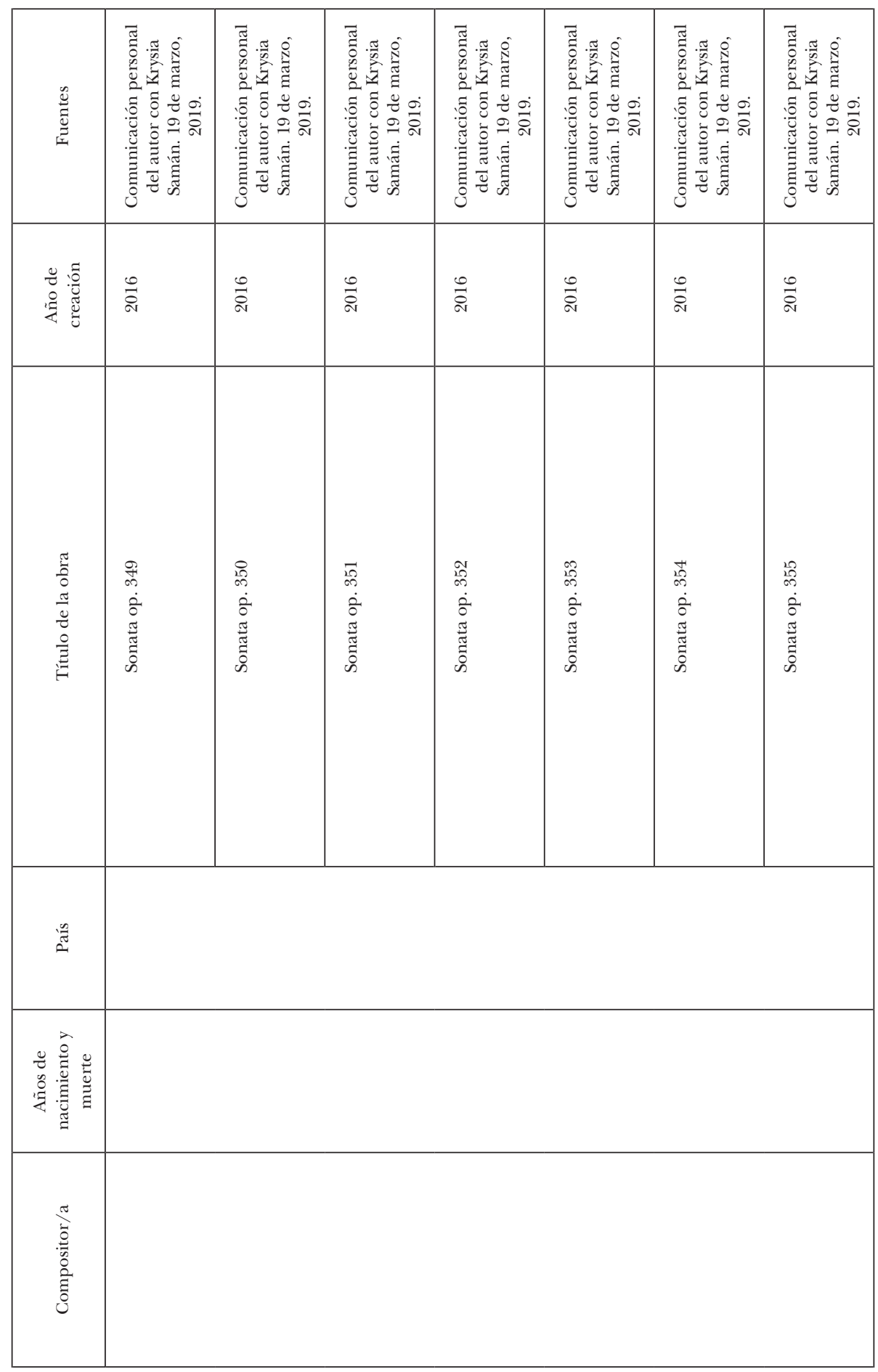




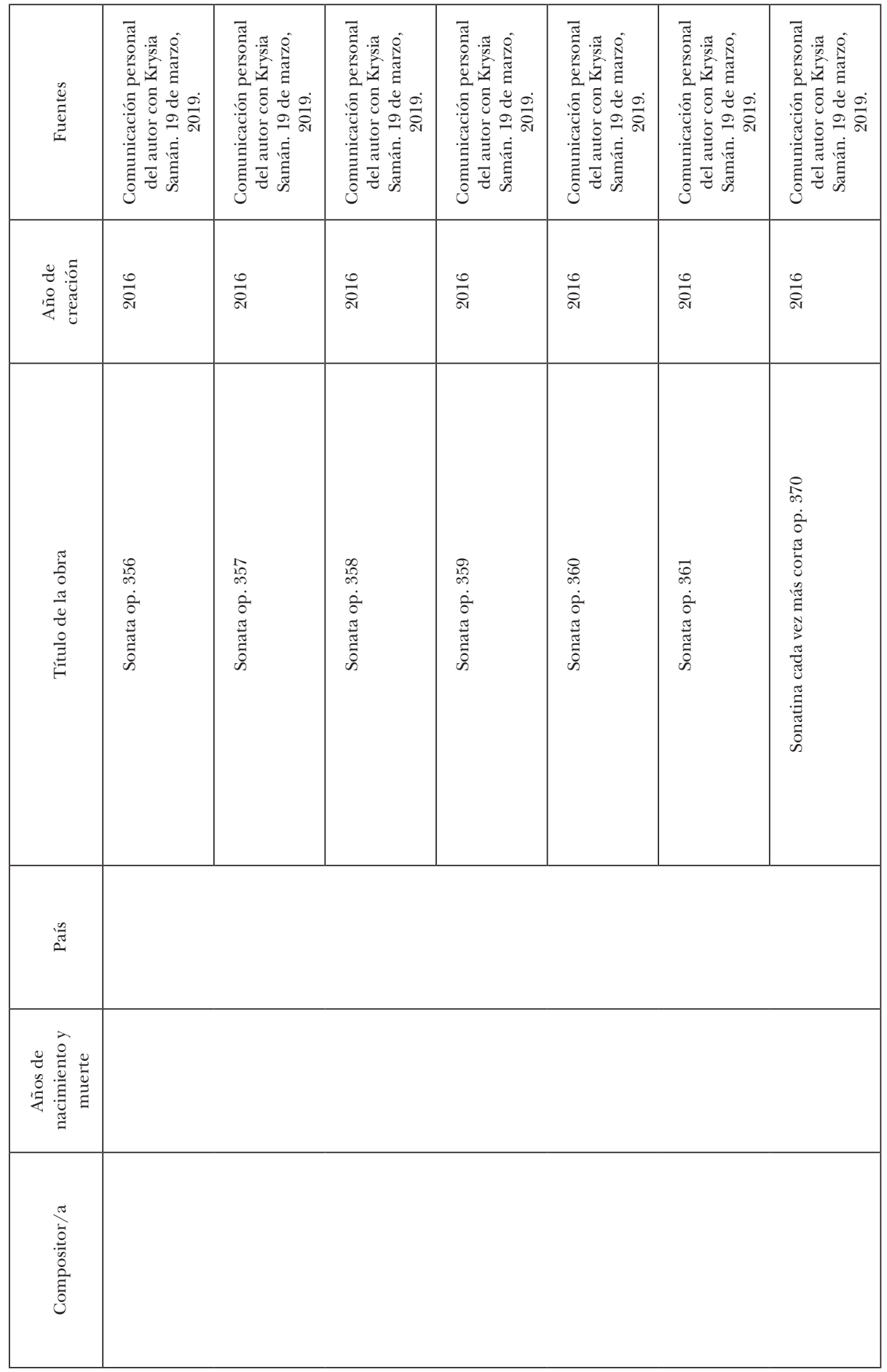




\begin{tabular}{|c|c|c|c|c|c|c|c|}
\hline 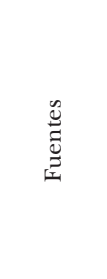 & 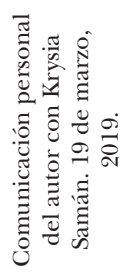 & 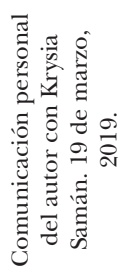 & 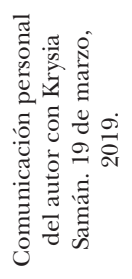 & 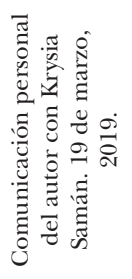 & 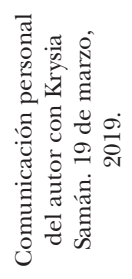 & 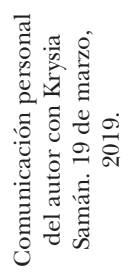 & 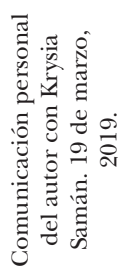 \\
\hline 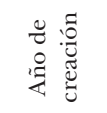 & $\stackrel{\bullet}{\stackrel{\leftrightarrow}{*}}$ & $\begin{array}{l}\stackrel{0}{\circ} \\
\stackrel{\sim}{\sim}\end{array}$ & $\stackrel{0}{\stackrel{0}{\sigma}}$ & $\stackrel{0}{\stackrel{0}{0}}$ & 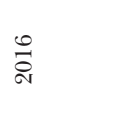 & $\stackrel{0}{\stackrel{0}{\Delta}}$ & 옹 \\
\hline $\begin{array}{l}\frac{\pi}{0} \\
\frac{\pi}{0} \\
\frac{\pi}{0} \\
\frac{0}{0} \\
\frac{0}{E} \\
\frac{D}{E}\end{array}$ & 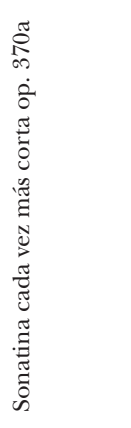 & 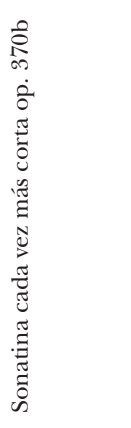 & 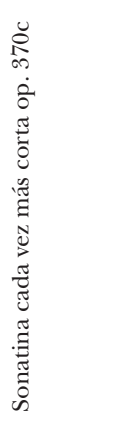 & 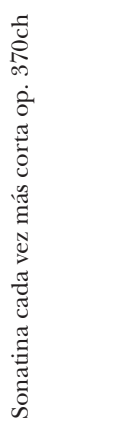 & 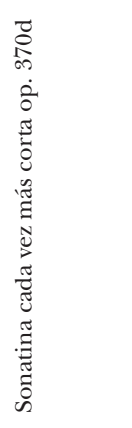 & 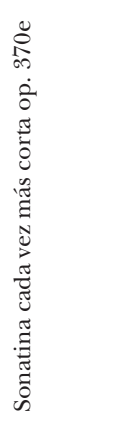 & 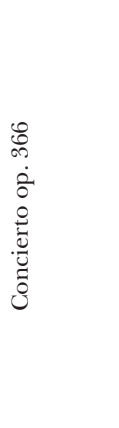 \\
\hline 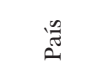 & & & & & & & \\
\hline 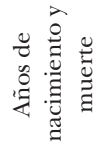 & & & & & & & \\
\hline 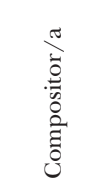 & & & & & & & \\
\hline
\end{tabular}




\begin{tabular}{|c|c|c|c|c|c|c|c|c|c|}
\hline 莺 & 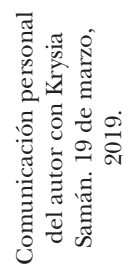 & 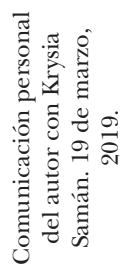 & 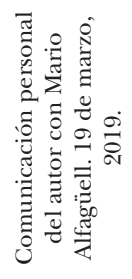 & 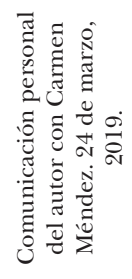 & 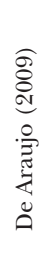 & 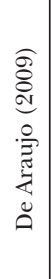 & 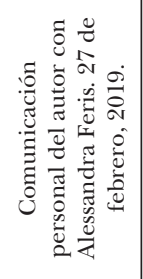 & 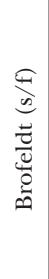 & 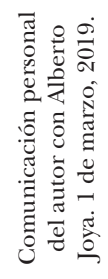 \\
\hline 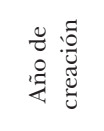 & 옹 & 옹 & 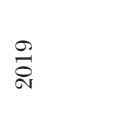 & $\stackrel{\stackrel{\Omega}{a}}{\stackrel{a}{v}}$ & 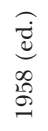 & $\begin{array}{l}\overrightarrow{\mathrm{D}} \\
\text { जे }\end{array}$ & \& & $\begin{array}{l}\text { oे } \\
\text { هั }\end{array}$ & $\frac{\Gamma}{\infty}$ \\
\hline $\begin{array}{l}\frac{\pi}{0} \\
0 \\
\frac{\pi}{0} \\
\frac{\pi}{0} \\
0 \\
\frac{0}{\Xi}\end{array}$ & 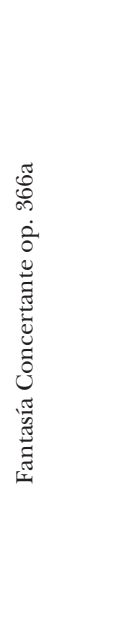 & 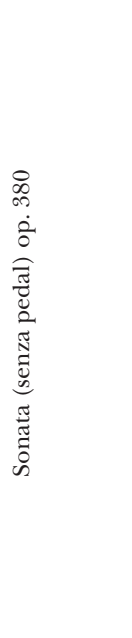 & 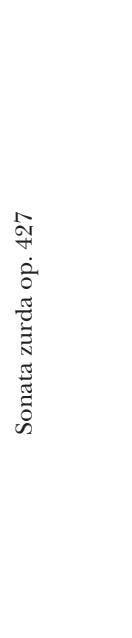 & 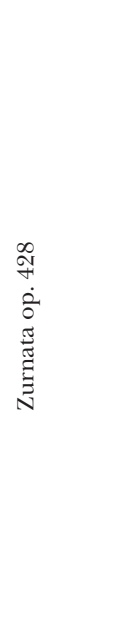 & 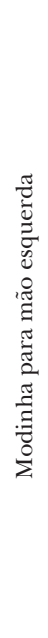 & 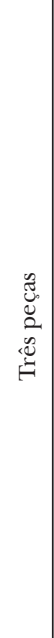 & 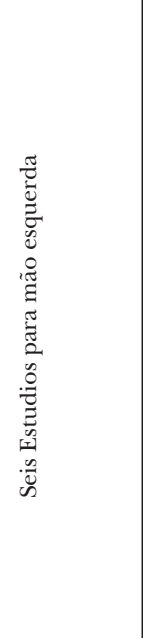 & 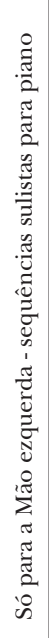 & 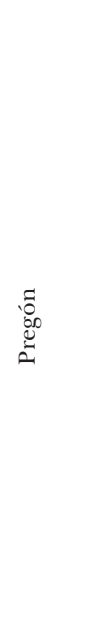 \\
\hline$\stackrel{n}{\tilde{N}}$ & & & & & 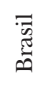 & & 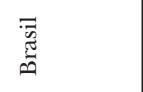 & 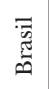 & $\frac{\tilde{E}}{\tilde{\Xi}}$ \\
\hline 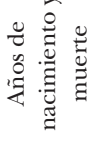 & & & & & 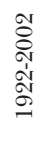 & & $\begin{array}{l}\stackrel{8}{\mathscr{E}} \\
\stackrel{\dot{g}}{ }\end{array}$ & 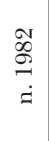 & 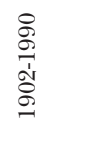 \\
\hline 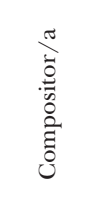 & & & & & 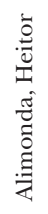 & & 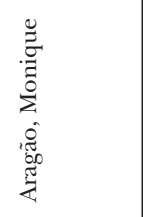 & 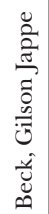 & 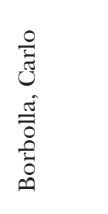 \\
\hline
\end{tabular}




\begin{tabular}{|c|c|c|c|c|c|c|c|c|c|c|c|}
\hline 萢 & 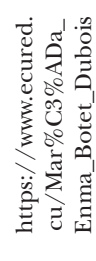 & 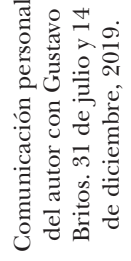 & 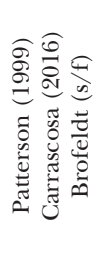 & 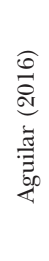 & 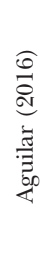 & 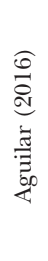 & 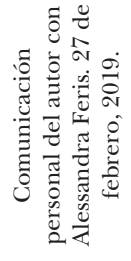 & 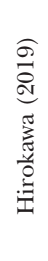 & 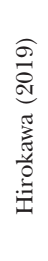 & 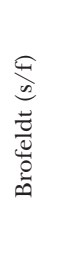 & 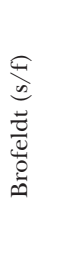 \\
\hline 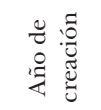 & $\begin{array}{l}\text { Ñ } \\
\stackrel{5}{=}\end{array}$ & 尽 & 忘 & 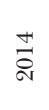 & 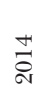 & 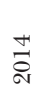 & $\stackrel{\infty}{\stackrel{\circ}{\varrho}}$ & 命 & 离 & 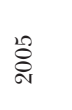 & $\begin{array}{l}\text { ષั } \\
\text { ज. }\end{array}$ \\
\hline $\begin{array}{l}\frac{\pi}{0} \\
0 \\
\frac{\pi}{0} \\
0 \\
0 \\
0 \\
0\end{array}$ & 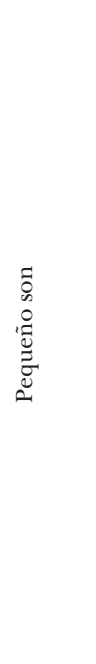 & 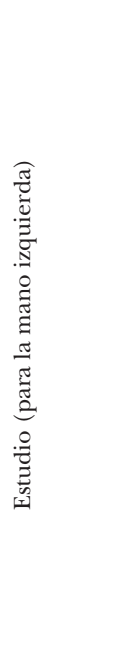 & 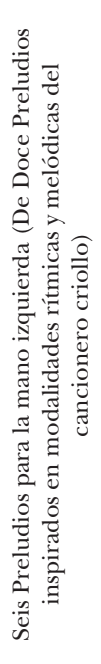 & 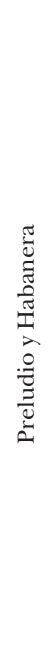 & 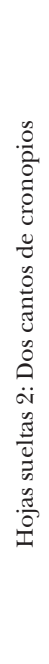 & 蒙 & 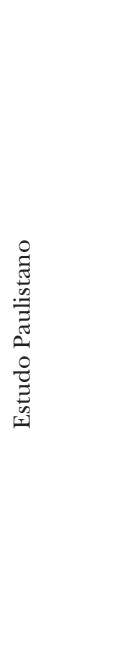 & 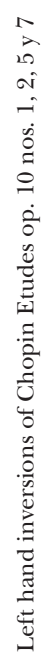 & 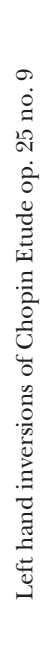 & 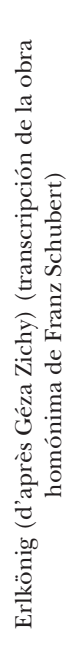 & 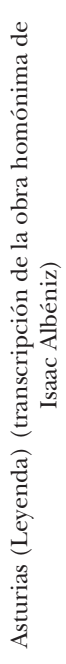 \\
\hline$\stackrel{\frac{n}{\pi}}{\tilde{E}}$ & $\frac{\tilde{\sigma}}{\tilde{\Xi}}$ & 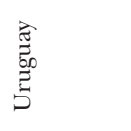 & 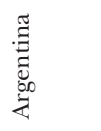 & $\begin{array}{l}\frac{\pi}{2} \\
\frac{\pi}{0} \\
0 \\
0\end{array}$ & $\begin{array}{l}\frac{\pi}{2} \\
\frac{\pi}{2} \\
0 \\
0\end{array}$ & $\begin{array}{l}\frac{\pi}{2} \\
\frac{\pi}{20} \\
\frac{\pi}{0} \\
0\end{array}$ & 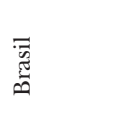 & 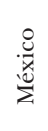 & & 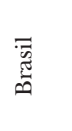 & \\
\hline 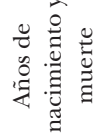 & 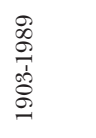 & $\begin{array}{l}\vec{F} \\
\stackrel{g}{g}\end{array}$ & 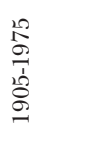 & $\begin{array}{l}\stackrel{8}{\mathscr{E}} \\
\stackrel{a}{a}\end{array}$ & $\begin{array}{l}\stackrel{\mathscr{8}}{2} \\
\stackrel{9}{\dot{g}}\end{array}$ & $\begin{array}{l}\underset{N}{N} \\
\stackrel{5}{g} \\
\dot{=}\end{array}$ & $\begin{array}{l}\stackrel{8}{\circ} \\
\stackrel{2}{9}\end{array}$ & $\begin{array}{l}\infty \\
\stackrel{\infty}{\sigma} \\
\frac{1}{1} \\
\stackrel{8}{\infty} \\
-\end{array}$ & & 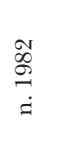 & \\
\hline 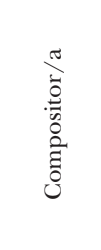 & 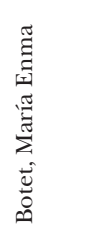 & 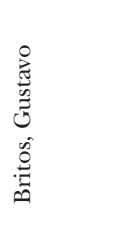 & 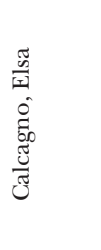 & 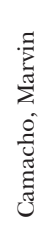 & 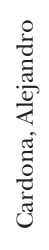 & 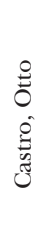 & 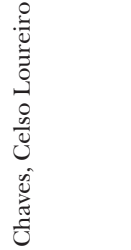 & 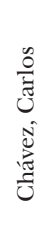 & & 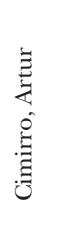 & \\
\hline
\end{tabular}




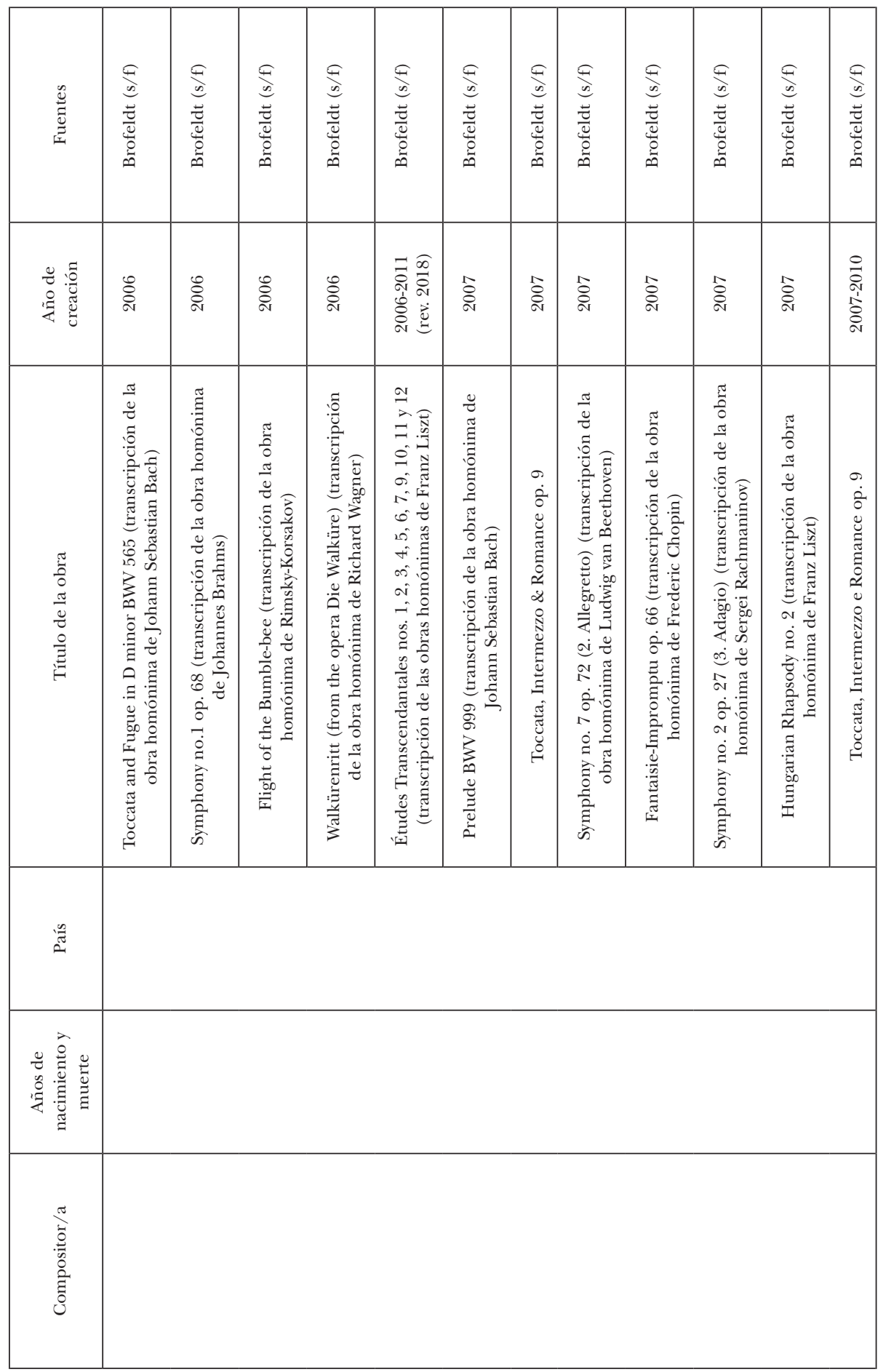




\begin{tabular}{|c|c|c|c|c|c|c|c|c|c|c|}
\hline 营 & 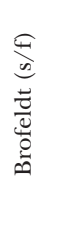 & 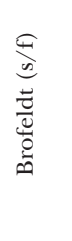 & 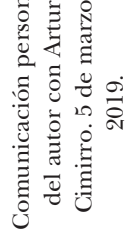 & 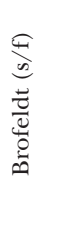 & 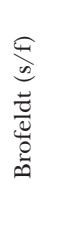 & 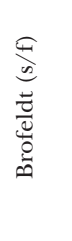 & 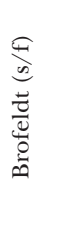 & 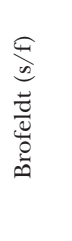 & 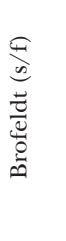 & 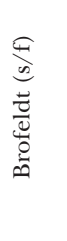 \\
\hline 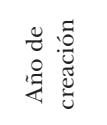 & $\begin{array}{l}\infty \\
\text { ڤे }\end{array}$ & 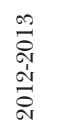 & $\stackrel{10}{\stackrel{2}{a}}$ & 光 & 尝 & $\stackrel{10}{\stackrel{2}{a}}$ & $\stackrel{10}{\stackrel{20}{\sim}}$ & $\stackrel{10}{\stackrel{2}{a}}$ & 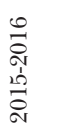 & $\stackrel{0}{\stackrel{\leftrightarrow}{*}}$ \\
\hline $\begin{array}{l}\frac{\pi}{0} \\
0 \\
\frac{\pi}{0} \\
\frac{0}{0} \\
0 \\
\frac{0}{3} \\
0\end{array}$ & 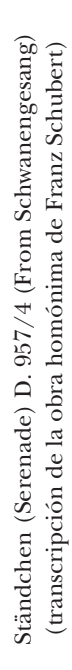 & 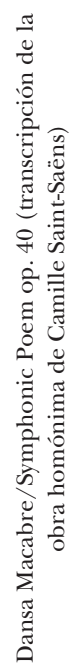 & 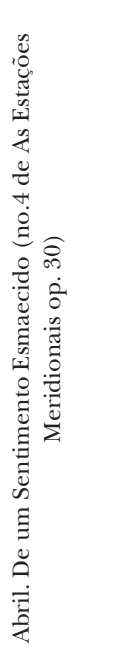 & 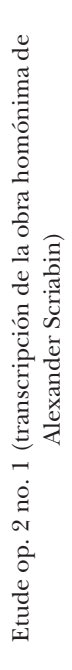 & 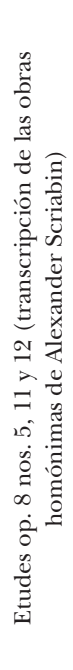 & 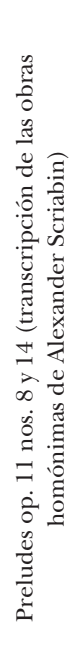 & 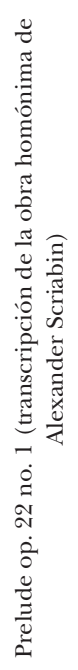 & 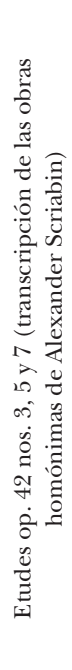 & 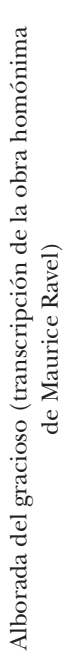 & 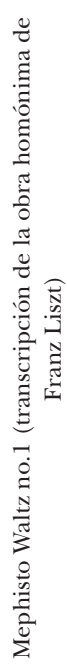 \\
\hline$\stackrel{\frac{\omega}{\pi}}{\pi}$ & & & & & & & & & & \\
\hline 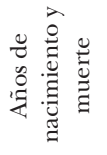 & & & & & & & & & & \\
\hline 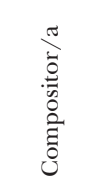 & & & & & & & & & & \\
\hline
\end{tabular}




\begin{tabular}{|c|c|c|c|c|c|c|c|c|}
\hline 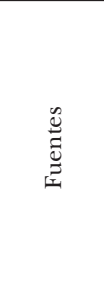 & 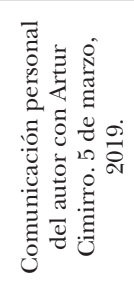 & 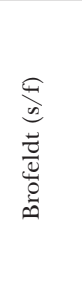 & 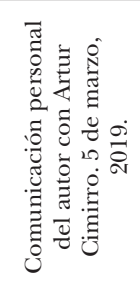 & 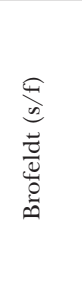 & 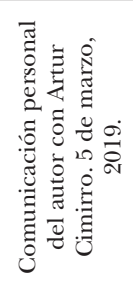 & 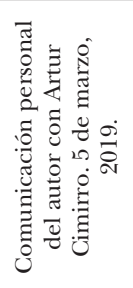 & 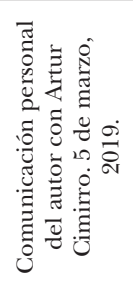 & 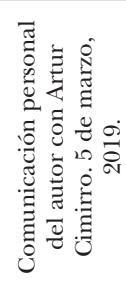 \\
\hline 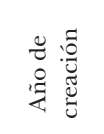 & $\begin{array}{l}0 \\
\stackrel{\text { İ }}{0}\end{array}$ & 号 & 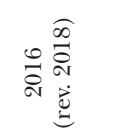 & 今ે & సัे & $\stackrel{\infty}{\stackrel{\text { जे }}{0}}$ & $\begin{array}{l}\infty \\
\stackrel{\text { I }}{N}\end{array}$ & $\stackrel{\infty}{\stackrel{\infty}{ล}}$ \\
\hline $\begin{array}{l}\frac{\pi}{0} \\
\frac{0}{0} \\
\frac{\pi}{0} \\
\frac{\pi}{0} \\
\frac{0}{E} \\
\frac{0}{n}\end{array}$ & 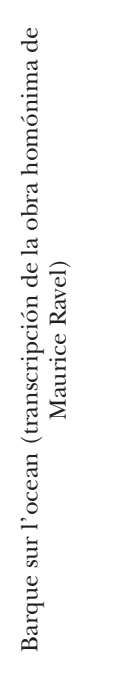 & 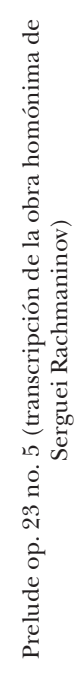 & $\begin{array}{l}0 \\
\infty \\
\dot{0} \\
\dot{0} \\
\tilde{\Xi} \\
\tilde{\Xi} \\
0 \\
0\end{array}$ & 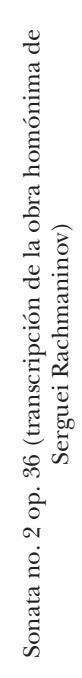 & 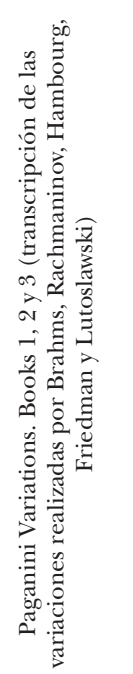 & 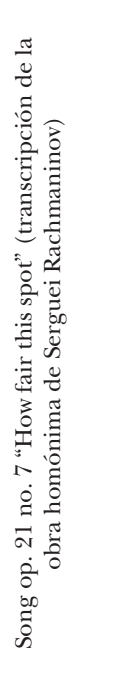 & 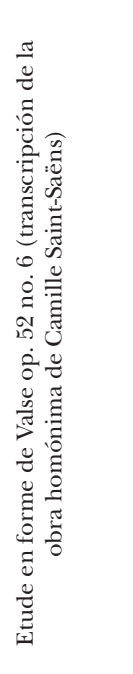 & 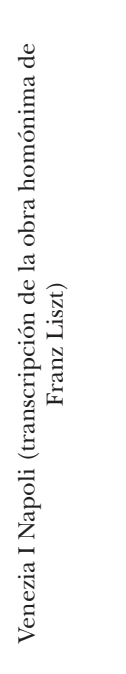 \\
\hline$\frac{n}{\tilde{z}}$ & & & & & & & & \\
\hline 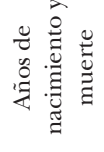 & & & & & & & & \\
\hline है & & & & & & & & \\
\hline
\end{tabular}




\begin{tabular}{|c|c|c|c|c|c|c|c|c|}
\hline 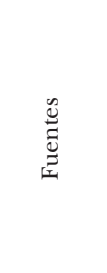 & 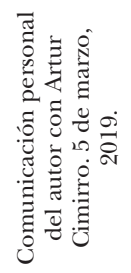 & 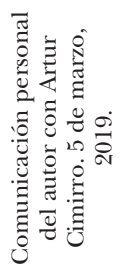 & 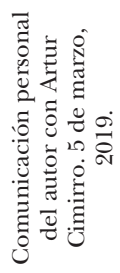 & 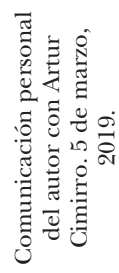 & 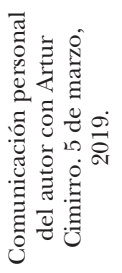 & 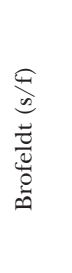 & 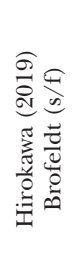 & 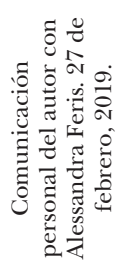 \\
\hline 娄: & $\stackrel{\infty}{\stackrel{\infty}{*}}$ & 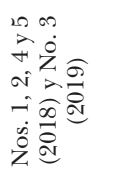 & 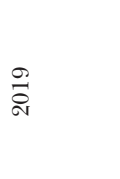 & 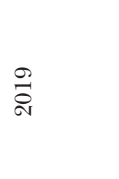 & 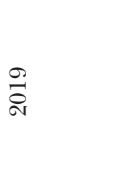 & $\underset{\sigma}{\sigma}$ & 鹃 & 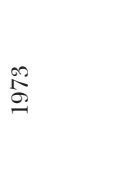 \\
\hline $\begin{array}{l}\frac{\pi}{0} \\
0 \\
\frac{\pi}{0} \\
0 \\
0 \\
\frac{0}{E} \\
0\end{array}$ & 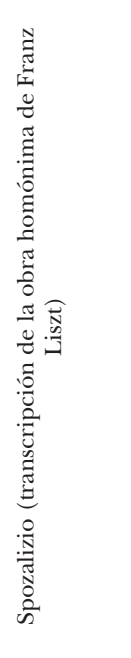 & 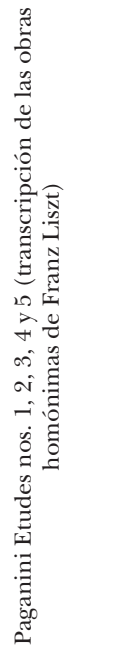 & 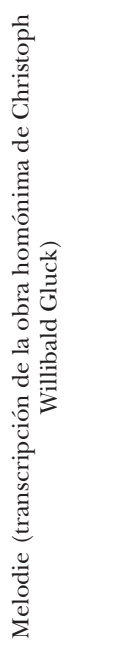 & 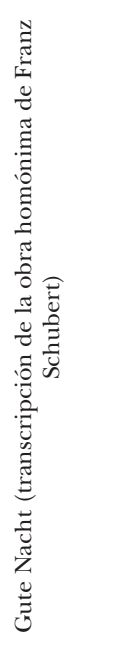 & 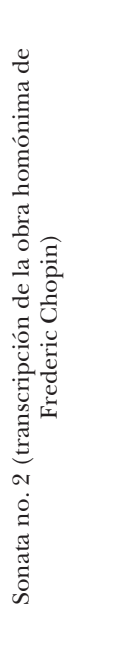 & 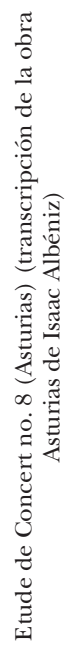 & 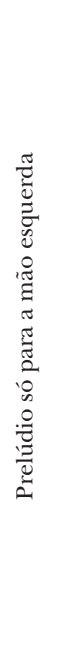 & 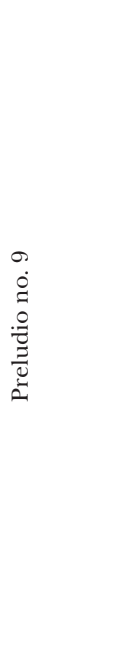 \\
\hline$\stackrel{n}{\tilde{E}}$ & & & & & & $\begin{array}{l}\overline{\bar{n}} \\
\stackrel{0}{0}\end{array}$ & $\begin{array}{l}\overline{\bar{n}} \\
\bar{n}\end{array}$ & $\begin{array}{l}\overline{\bar{n}} \\
\text { 氙 }\end{array}$ \\
\hline 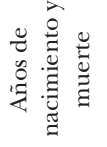 & & & & & & 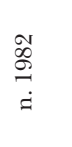 & 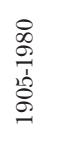 & 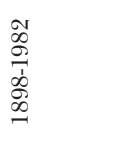 \\
\hline 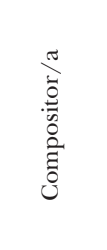 & & & & & & 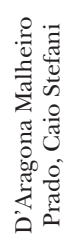 & 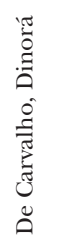 & 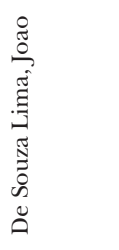 \\
\hline
\end{tabular}




\begin{tabular}{|c|c|c|c|c|c|c|c|c|c|c|c|c|c|}
\hline 总 & 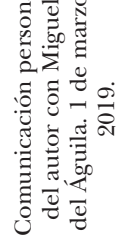 & 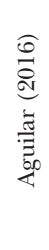 & 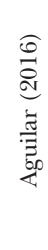 & 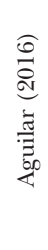 & 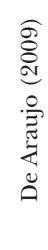 & 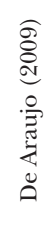 & 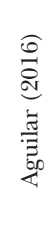 & 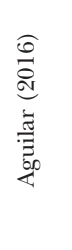 & 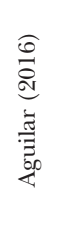 & 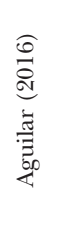 & 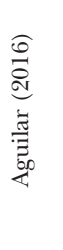 & 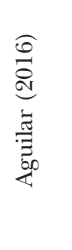 & 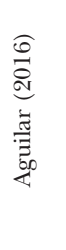 \\
\hline 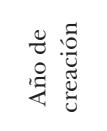 & ષ્ڤે & 总 & $\begin{array}{l}\text { H } \\
\text { aे }\end{array}$ & $\stackrel{10}{\stackrel{1}{*}}$ & बัे & 胥 & 水 & 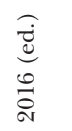 & 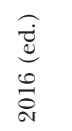 & 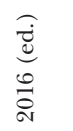 & 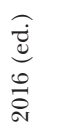 & 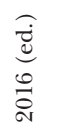 & 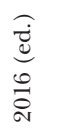 \\
\hline $\begin{array}{l}\frac{\pi}{0} \\
0 \\
\frac{\pi}{0} \\
\frac{\pi}{0} \\
0 \\
\frac{0}{\Xi} \\
0\end{array}$ & 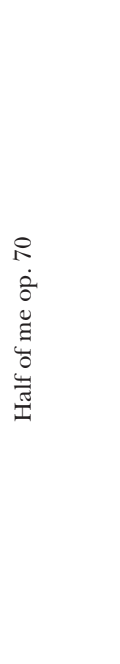 & 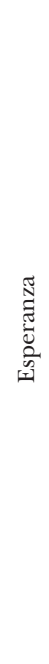 & 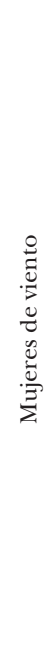 & 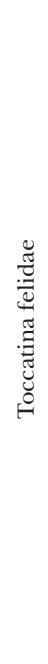 & 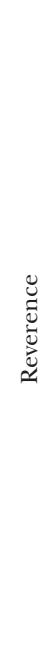 & 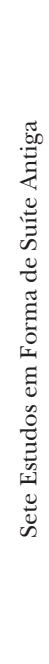 & 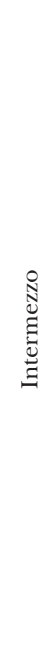 & 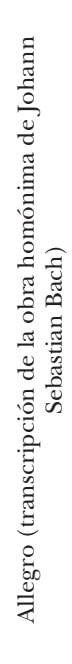 & 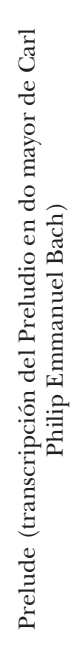 & 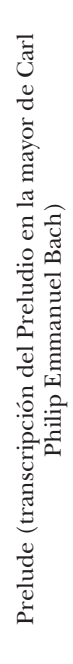 & 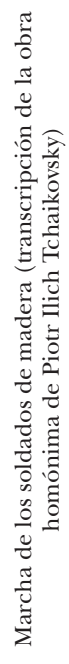 & 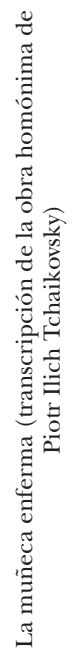 & 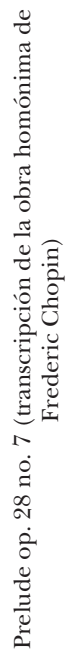 \\
\hline 彭 & 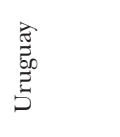 & 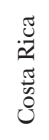 & 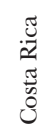 & & $\begin{array}{l}\overline{\bar{v}} \\
\overline{0} \\
0\end{array}$ & 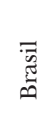 & 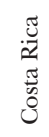 & & & & & & \\
\hline 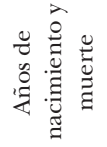 & $\begin{array}{l}\frac{1}{2} \\
\stackrel{\circ}{\leftrightarrows} \\
\dot{1}\end{array}$ & 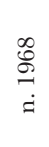 & 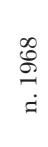 & & 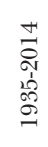 & 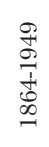 & $\begin{array}{l}\mathscr{S} \\
\text { S } \\
\dot{d}\end{array}$ & & & & & & \\
\hline 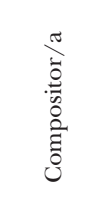 & 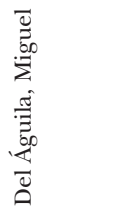 & 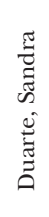 & 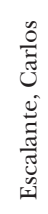 & & 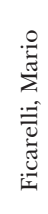 & 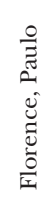 & $\begin{array}{l}\overline{\tilde{\Xi}} \\
\tilde{\Xi} \\
\tilde{n} \\
\tilde{\delta} \\
\tilde{\delta} \\
\tilde{\tilde{J}}\end{array}$ & & & & & & \\
\hline
\end{tabular}




\begin{tabular}{|c|c|c|c|c|c|c|c|c|c|c|}
\hline$\overbrace{\overrightarrow{0}}^{\infty}$ & 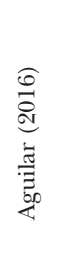 & 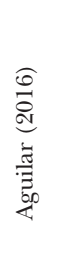 & 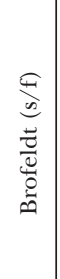 & 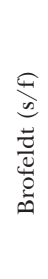 & 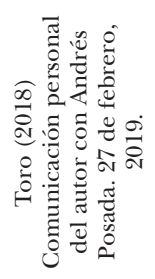 & 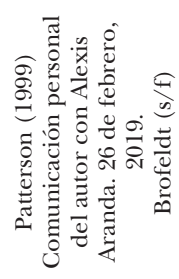 & 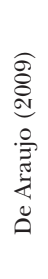 & 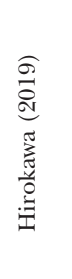 & 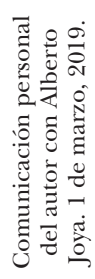 & 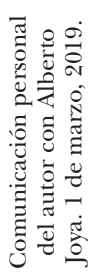 \\
\hline 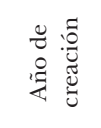 & 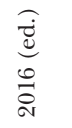 & 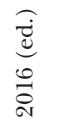 & 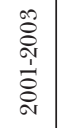 & 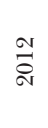 & 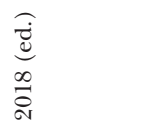 & $\overrightarrow{\mathscr{\sigma}}$ & $\begin{array}{l}\infty \\
\stackrel{\infty}{\circ} \\
\stackrel{-}{-}\end{array}$ & $\begin{array}{l}\mathbb{N} \\
\infty \\
\end{array}$ & \&. & $\frac{\pi}{\infty}$ \\
\hline $\begin{array}{l}\frac{\pi}{0} \\
\frac{0}{0} \\
\frac{\pi}{0} \\
\frac{0}{0} \\
\frac{0}{Z} \\
\frac{D}{0}\end{array}$ & 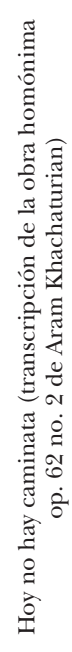 & 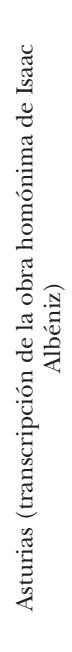 & 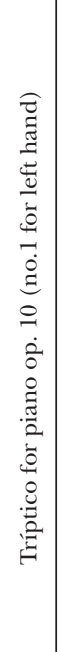 & $\begin{array}{l}\vec{\infty} \\
\dot{0} \\
0 \\
0 \\
0 \\
0 \\
0 \\
0 \\
0 \\
0\end{array}$ & 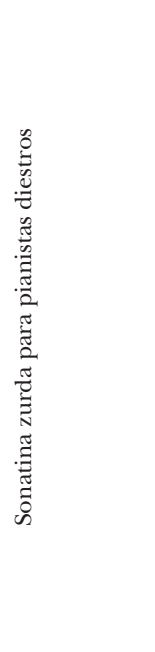 & 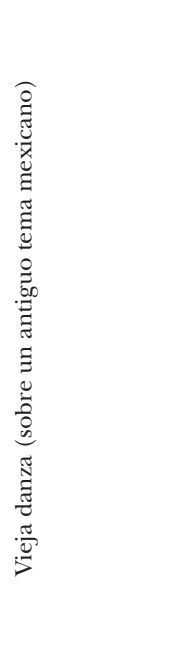 & 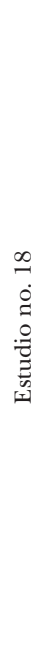 & 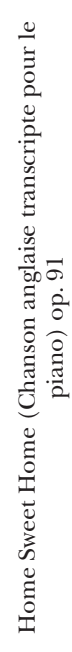 & 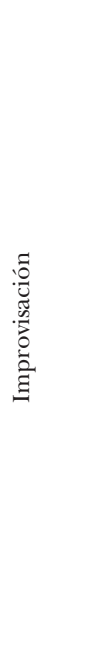 & 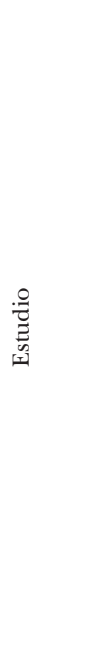 \\
\hline : & & & 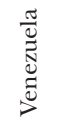 & & 号 & 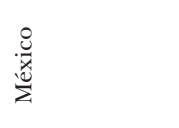 & $\begin{array}{l}\overline{\bar{v}} \\
\text { 氙 }\end{array}$ & 节 & $\frac{\pi}{3}$ & \\
\hline 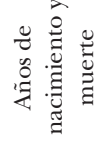 & & & 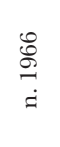 & & $\begin{array}{l}\stackrel{\circ}{\circ} \\
\stackrel{g}{g}\end{array}$ & $\begin{array}{l}\overrightarrow{0} \\
\mathscr{J} \\
\stackrel{D}{\infty} \\
\stackrel{0}{\sigma}\end{array}$ & $\begin{array}{l}\frac{n}{2} \\
\frac{\sigma}{1} \\
\frac{1}{8} \\
\frac{\sigma}{n}\end{array}$ & $\begin{array}{l}10 \\
\infty \\
\infty \\
1 \\
\infty \\
\infty \\
0\end{array}$ & $\begin{array}{l}\stackrel{\mathscr{Q}}{\text { gे }} \\
\stackrel{a}{ }\end{array}$ & \\
\hline 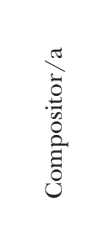 & & & 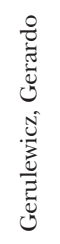 & & 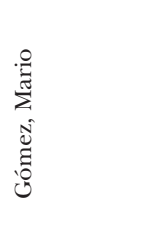 & 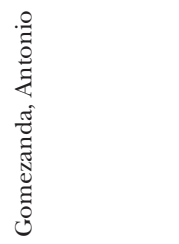 & 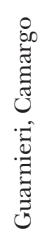 & 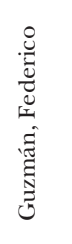 & 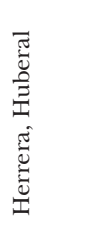 & \\
\hline
\end{tabular}




\begin{tabular}{|c|c|c|c|c|c|c|c|c|c|c|c|}
\hline 离 & 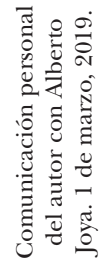 & 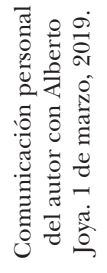 & 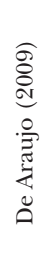 & 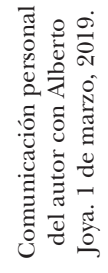 & 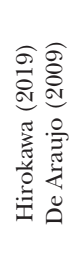 & 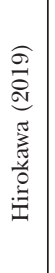 & 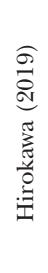 & 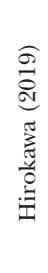 & 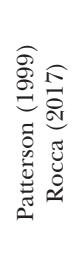 & 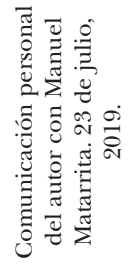 & 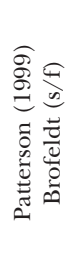 \\
\hline 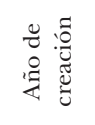 & $\frac{\tau}{\infty}$ & $\sum_{\infty}$ & $\begin{array}{l}\stackrel{10}{\circ} \\
\stackrel{9}{9}\end{array}$ & $\begin{array}{l}18 \\
\text { S. }\end{array}$ & 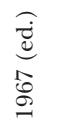 & \&े & 尽 & $\frac{\sigma}{\infty}$ & $\begin{array}{l}\mathscr{1 0} \\
\stackrel{8}{9}\end{array}$ & 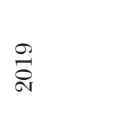 & 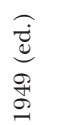 \\
\hline $\begin{array}{l}\frac{\pi}{0} \\
0 \\
\frac{\pi}{0} \\
\frac{\pi}{0} \\
0 \\
\frac{0}{3} \\
0\end{array}$ & 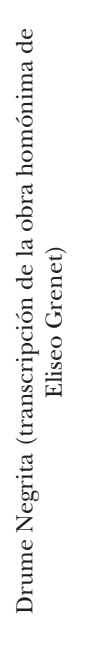 & 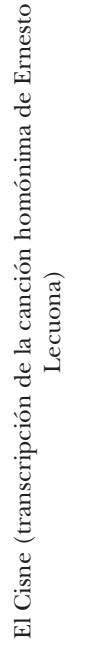 & 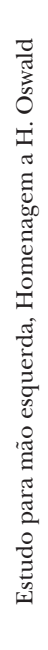 & 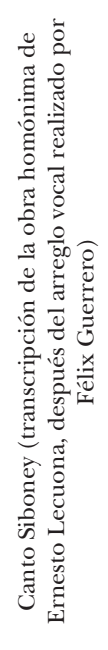 & 苞 & 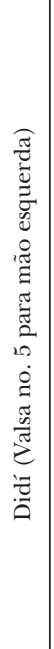 & 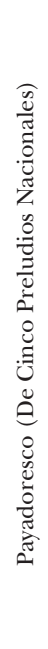 & 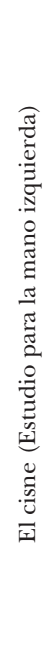 & 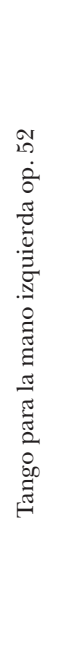 & 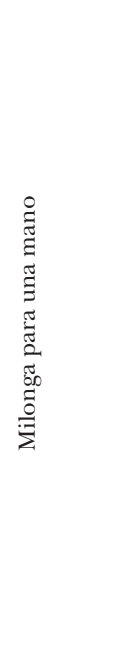 & 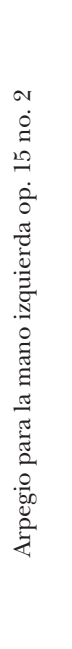 \\
\hline$\stackrel{n}{\pi}$ & & & 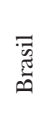 & है & 氶 & & 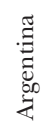 & $\stackrel{\widetilde{\sigma}}{\Xi}$ & 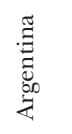 & 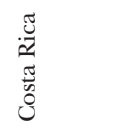 & ؛ัँ \\
\hline 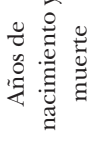 & & & $\begin{array}{l}\stackrel{\infty}{2} \\
\text { बै } \\
\dot{a}\end{array}$ & $\begin{array}{l}\text { I } \\
\text { Oे } \\
\dot{9} \\
\dot{9}\end{array}$ & 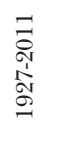 & & 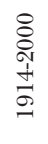 & 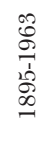 & $\begin{array}{l}\infty \\
\infty \\
\stackrel{0}{1} \\
\infty \\
\stackrel{\sigma}{\sigma}\end{array}$ & 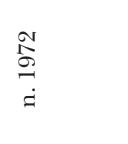 & $\begin{array}{l}\stackrel{\circ}{\circ} \\
\stackrel{\circ}{a} \\
\dot{a}\end{array}$ \\
\hline 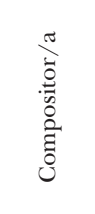 & & & 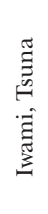 & 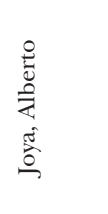 & 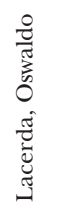 & & 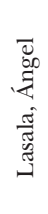 & 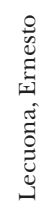 & 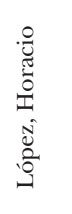 & 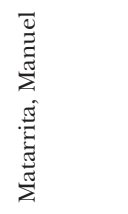 & 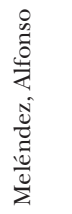 \\
\hline
\end{tabular}




\begin{tabular}{|c|c|c|c|c|c|c|c|c|c|c|}
\hline 苞 & 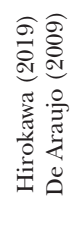 & 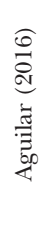 & 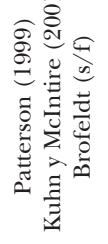 & 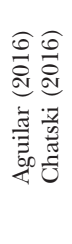 & 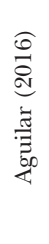 & 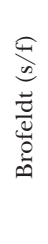 & 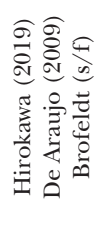 & 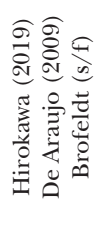 & 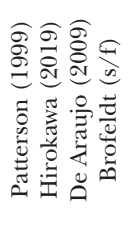 & 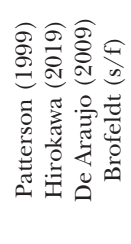 \\
\hline 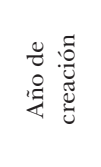 & 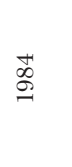 & $\underset{\stackrel{\sim}{*}}{+}$ & 窇 & $\underset{\text { İ }}{+}$ & 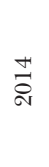 & 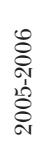 & 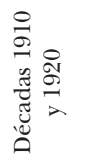 & $\begin{array}{l}\text { Eे } \\
\stackrel{\Xi}{\sigma}\end{array}$ & $\stackrel{\Xi}{\leftrightarrows}$ & $\stackrel{\circ}{\sigma}$ \\
\hline $\begin{array}{l}\frac{\pi}{0} \\
0 \\
\frac{\pi}{0} \\
0 \\
0 \\
0 \\
0 \\
0\end{array}$ & 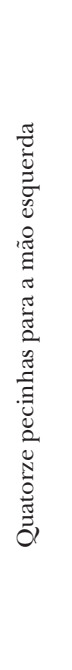 & 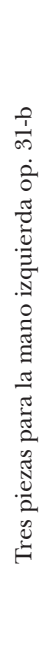 & 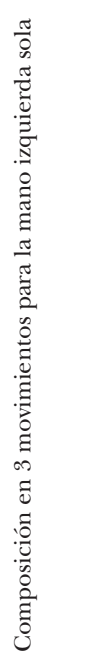 & 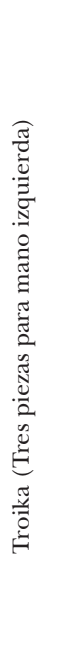 & 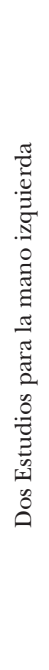 & 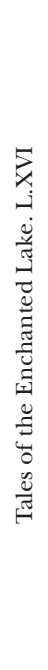 & 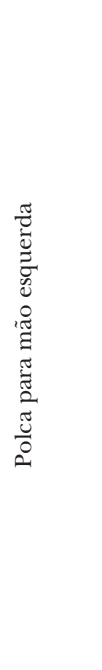 & 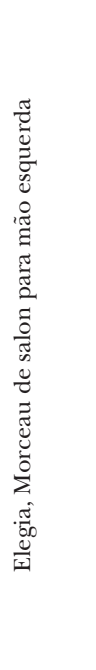 & 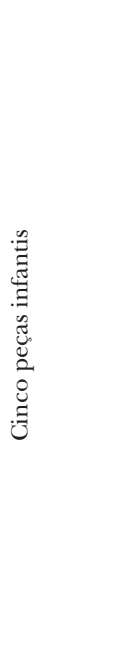 & 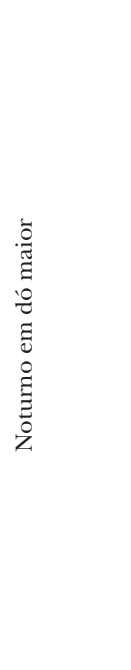 \\
\hline$\stackrel{n}{\pi}$ & 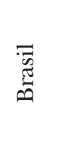 & $\begin{array}{l}\frac{\pi}{2} \\
\frac{\pi}{0} \\
\frac{\pi}{0} \\
0\end{array}$ & 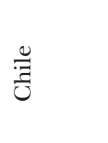 & $\frac{\pi}{\frac{\pi}{2}}$ & $\begin{array}{l}\frac{\pi}{2} \\
\frac{\pi}{5} \\
\frac{\pi}{0} \\
0\end{array}$ & 总 & 馬 & & 胥 & \\
\hline 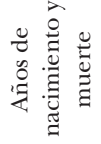 & 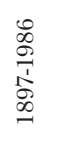 & $\begin{array}{l}\stackrel{\mathscr{Q}}{\mathscr{g}} \\
\dot{g}\end{array}$ & 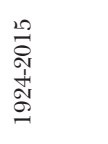 & $\begin{array}{l}\stackrel{8}{8} \\
\stackrel{8}{2} \\
\dot{a}\end{array}$ & $\begin{array}{l}\text { 点 } \\
\text { ○ } \\
\dot{a}\end{array}$ & $\begin{array}{l}\text { E } \\
\text { S } \\
\dot{a}\end{array}$ & 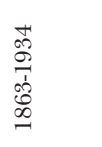 & & 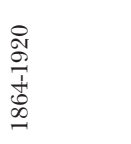 & \\
\hline 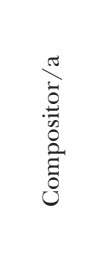 & 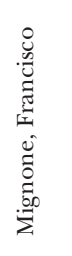 & 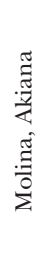 & 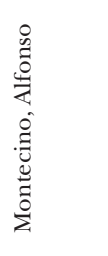 & 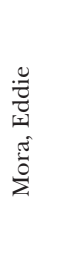 & 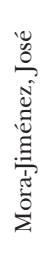 & 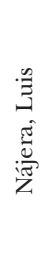 & 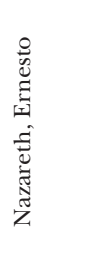 & & 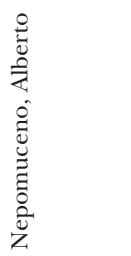 & \\
\hline
\end{tabular}




\begin{tabular}{|c|c|c|c|c|c|c|c|c|}
\hline 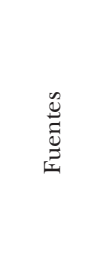 & 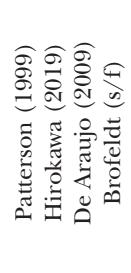 & 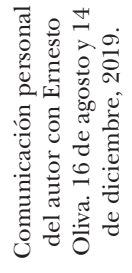 & 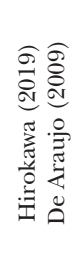 & 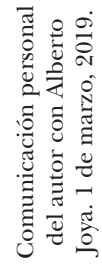 & 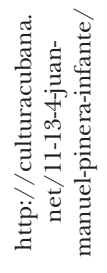 & 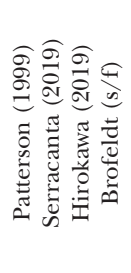 & 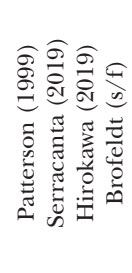 & 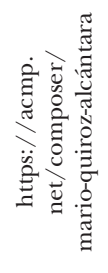 \\
\hline 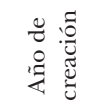 & $\frac{\mathfrak{v}}{\sigma}$ & $\stackrel{0}{\stackrel{0}{*}}$ & ब్ & $\frac{\tau}{\omega}$ & 古 & 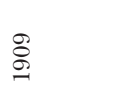 & $\begin{array}{l}\vec{\sigma} \\
\stackrel{\sigma}{\sigma}\end{array}$ & 今. \\
\hline $\begin{array}{l}\frac{\pi}{3} \\
0 \\
\frac{\pi}{0} \\
\frac{\pi}{0} \\
0 \\
\frac{0}{3}\end{array}$ & 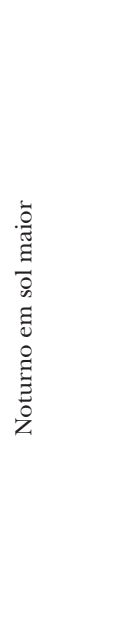 & 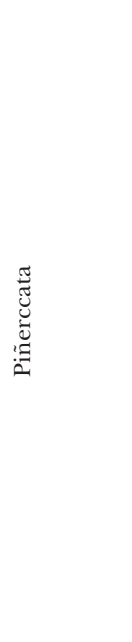 & 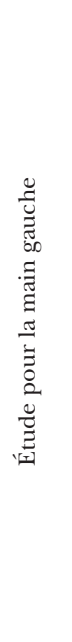 & 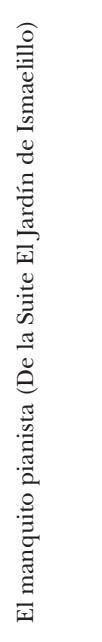 & 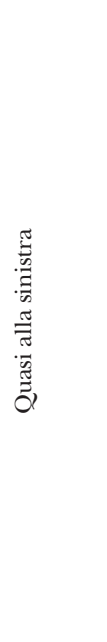 & 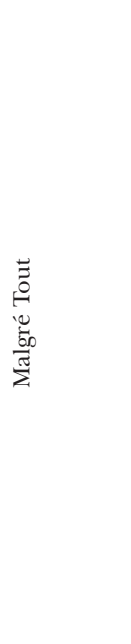 & 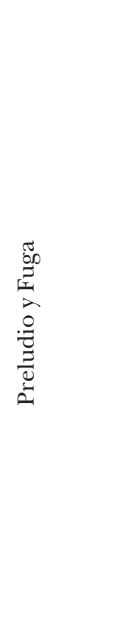 & 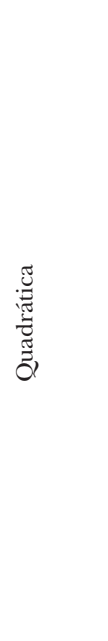 \\
\hline$\stackrel{n}{\tilde{N}}$ & & हَّ & 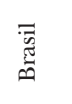 & हुँ & हَّ & 总 & & 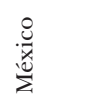 \\
\hline 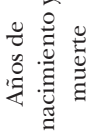 & & $\begin{array}{l}\infty \\
\stackrel{\infty}{\circ} \\
\stackrel{a}{a}\end{array}$ & $\begin{array}{l}\vec{\infty} \\
\stackrel{2}{\overline{1}} \\
\text { D̀ } \\
\infty \\
\infty\end{array}$ & 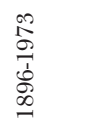 & $\begin{array}{l}\stackrel{\mathscr{P}}{\mathrm{g}} \\
\stackrel{9}{\dot{g}}\end{array}$ & \begin{tabular}{l}
$\infty$ \\
\multirow{2}{*}{} \\
$\stackrel{1}{1}$ \\
$\infty$ \\
$\infty$ \\
$\infty$ \\
$\infty$
\end{tabular} & & $\begin{array}{l}\mathscr{O} \\
\stackrel{g}{9} \\
\dot{a}\end{array}$ \\
\hline 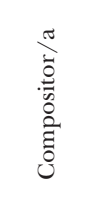 & & 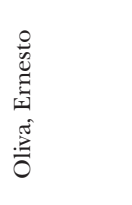 & 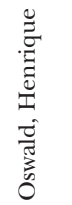 & 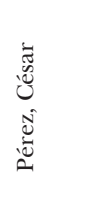 & 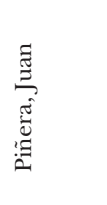 & 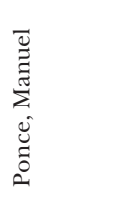 & & 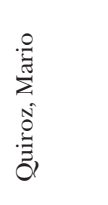 \\
\hline
\end{tabular}




\begin{tabular}{|c|c|c|c|c|c|c|c|c|c|c|c|c|}
\hline 岂 & 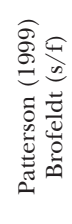 & 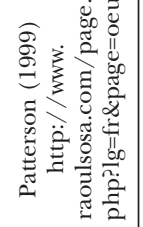 & 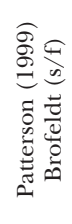 & 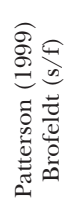 & 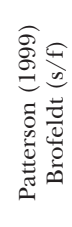 & 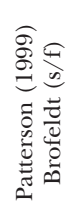 & 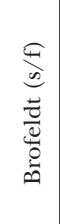 & 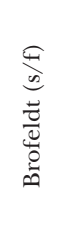 & 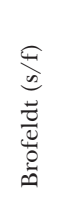 & 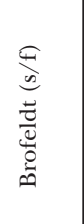 & 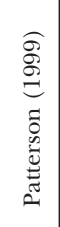 & 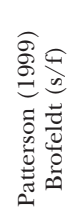 \\
\hline 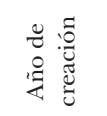 & $\begin{array}{l}\text { 艹 } \\
\stackrel{\circ}{\sigma}\end{array}$ & 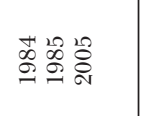 & 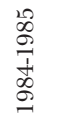 & 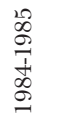 & $\begin{array}{l}\stackrel{\leftrightarrow}{\infty} \\
\stackrel{\Omega}{\sim}\end{array}$ & $\begin{array}{l}\infty \\
\stackrel{\infty}{\circ} \\
\stackrel{\Omega}{\sim}\end{array}$ & $\begin{array}{l}\infty \\
\stackrel{\infty}{=}\end{array}$ & $\begin{array}{l}\infty \\
\stackrel{\infty}{g}\end{array}$ & $\stackrel{\mathscr{\rho}}{\stackrel{\mathscr{\rho}}{二}}$ & $\stackrel{\mathscr{\sigma}}{\mathscr{\sigma}}$ & 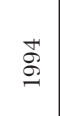 & 尽 \\
\hline $\begin{array}{l}\frac{\pi}{0} \\
0 \\
\frac{\pi}{0} \\
\frac{0}{0} \\
\frac{O}{E} \\
\frac{B}{6}\end{array}$ & $\begin{array}{l}\overrightarrow{0} \\
\dot{\Xi} \\
\tilde{\Xi} \\
\tilde{\Xi} \\
\tilde{n}\end{array}$ & 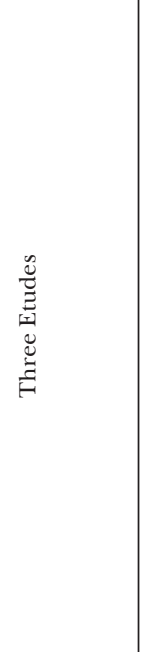 & 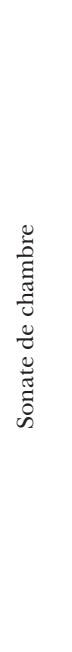 & 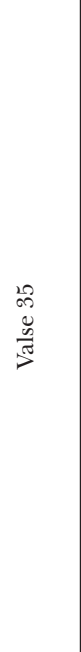 & 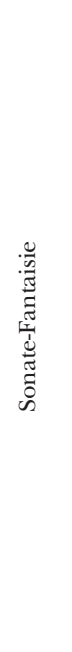 & ¿ & 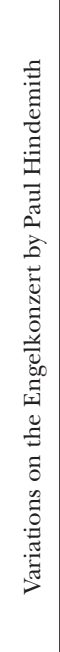 & 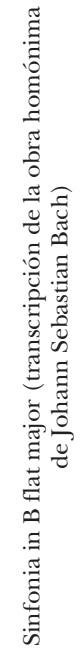 & 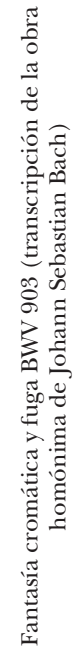 & 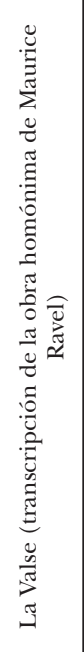 & 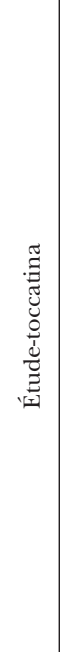 & 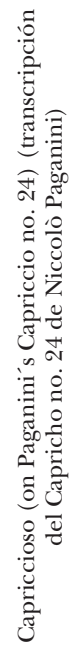 \\
\hline$\stackrel{\frac{n}{\pi}}{\pi}$ & 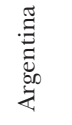 & & & & & & & & & & & \\
\hline 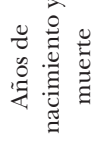 & $\begin{array}{l}\stackrel{\mathscr{g}}{g} \\
\stackrel{9}{\dot{a}}\end{array}$ & & & & & & & & & & & \\
\hline 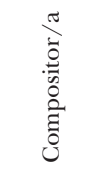 & 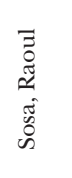 & & & & & & & & & & & \\
\hline
\end{tabular}




\begin{tabular}{|c|c|c|c|c|c|c|c|c|c|c|c|}
\hline 岂 & 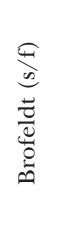 & 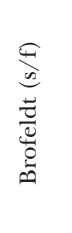 & 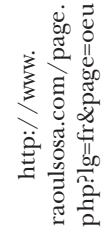 & 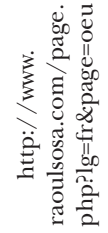 & 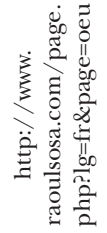 & 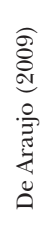 & 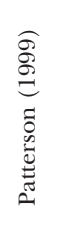 & 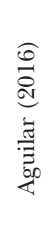 & 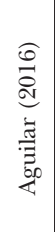 & 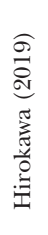 & 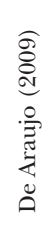 \\
\hline 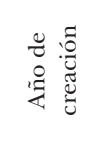 & \& & 合 & $\begin{array}{l}\text { ڤั } \\
\text { जั }\end{array}$ & ڤั̆ & $\begin{array}{l}\stackrel{\text { }}{\text { जे }} \\
\text { in }\end{array}$ & 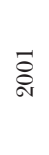 & 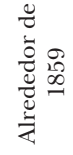 & 范 & $\underset{\text { à }}{*}$ & $\tilde{\sigma}$ & $\overrightarrow{\text { a }}$ \\
\hline $\begin{array}{l}\frac{\pi}{0} \\
\frac{0}{0} \\
\frac{\pi}{3} \\
\frac{\pi}{0} \\
0 \\
\frac{0}{3}\end{array}$ & 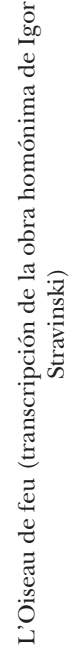 & 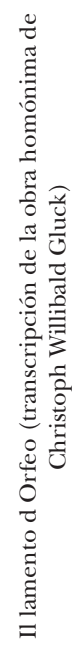 & 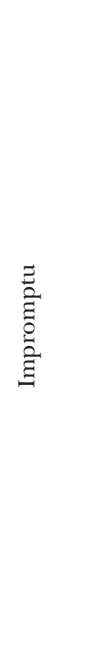 & 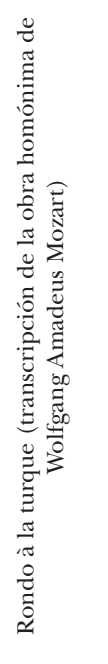 & 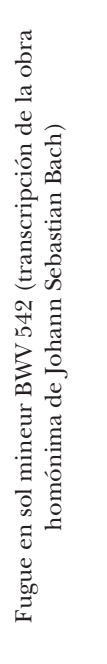 & 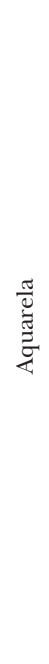 & 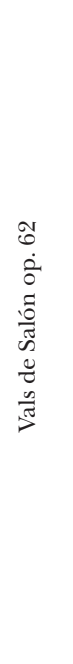 & 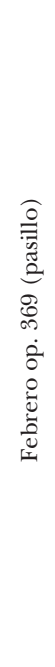 & 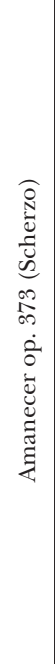 & 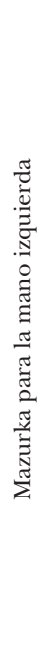 & 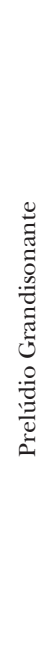 \\
\hline$\frac{\sqrt{2}}{\tilde{2}}$ & & & & & & 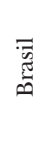 & 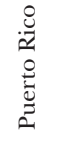 & 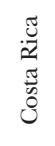 & & $\begin{array}{l}\frac{\pi}{0} \\
\frac{0}{0} \\
\text { 음 }\end{array}$ & $\begin{array}{l}\overline{\bar{v}} \\
\bar{g} \\
0\end{array}$ \\
\hline 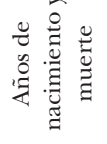 & & & & & & $\begin{array}{l}\stackrel{\mathscr{m}}{\leftrightarrows} \\
\stackrel{\dot{g}}{ }\end{array}$ & $\begin{array}{l}\infty \\
\infty \\
\infty \\
0 \\
0 \\
0 \\
\infty \\
0\end{array}$ & $\begin{array}{l}\stackrel{g}{S} \\
\stackrel{9}{g}\end{array}$ & & 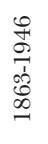 & 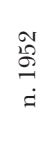 \\
\hline 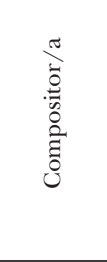 & & & & & & 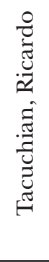 & 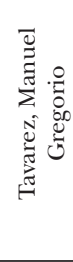 & 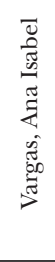 & & 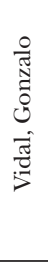 & 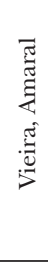 \\
\hline
\end{tabular}




\begin{tabular}{|c|c|c|c|c|c|}
\hline 节 & 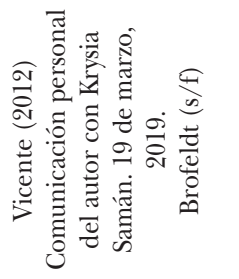 & 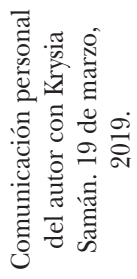 & 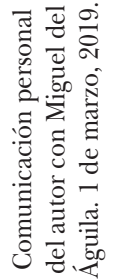 & 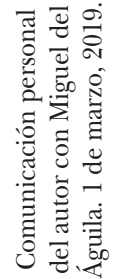 & 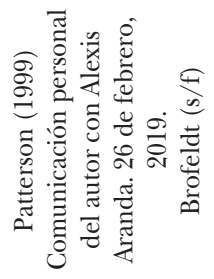 \\
\hline 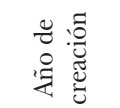 & $\stackrel{\vec{\circ}}{\stackrel{g}{\sigma}}$ & $\overline{\widetilde{\sigma}}$ & $\begin{array}{l}\mathscr{D} \\
\stackrel{\Omega}{\sigma}\end{array}$ & $\begin{array}{l}\mathscr{\circ} \\
\stackrel{\circ}{\sigma}\end{array}$ & $\stackrel{\vec{\sigma}}{\mathscr{\sigma}}$ \\
\hline 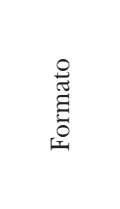 & 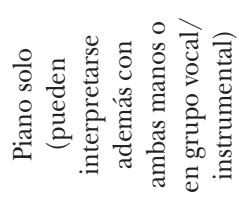 & 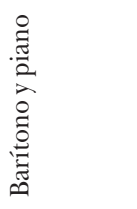 & 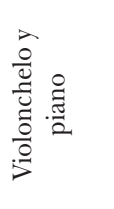 & 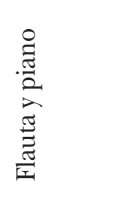 & 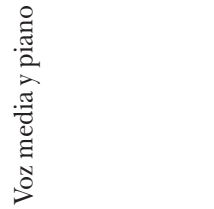 \\
\hline $\begin{array}{l}\frac{\pi}{0} \\
0 \\
\frac{\pi}{0} \\
\frac{\pi}{0} \\
0 \\
\frac{0}{3}\end{array}$ & 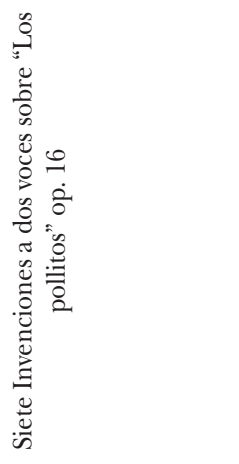 & 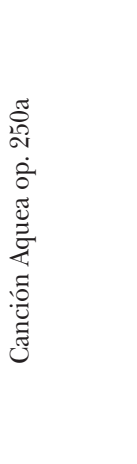 & 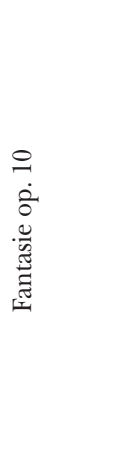 & 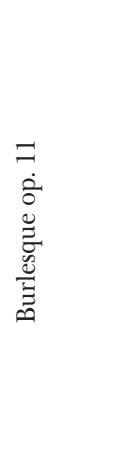 & 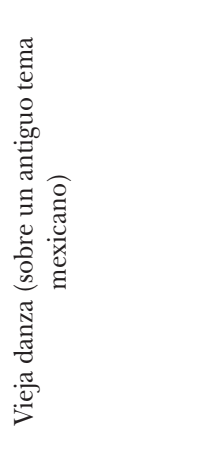 \\
\hline 芯 & \multicolumn{2}{|l|}{ 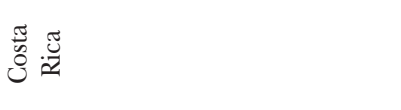 } & \multicolumn{2}{|l|}{ 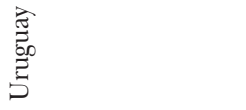 } & 离 \\
\hline 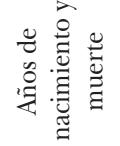 & \multicolumn{2}{|l|}{$\begin{array}{l}\frac{\infty}{5} \\
\stackrel{9}{a} \\
\dot{=}\end{array}$} & \multicolumn{2}{|l|}{$\begin{array}{l}\text { 合 } \\
\text { ¿ }\end{array}$} & 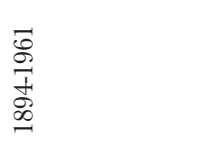 \\
\hline 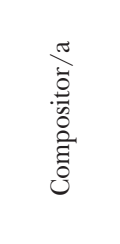 & \multicolumn{2}{|l|}{ 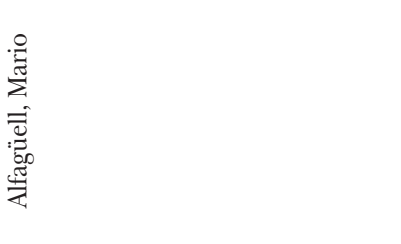 } & \multicolumn{2}{|l|}{ 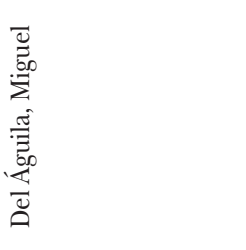 } & 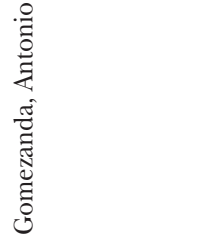 \\
\hline
\end{tabular}




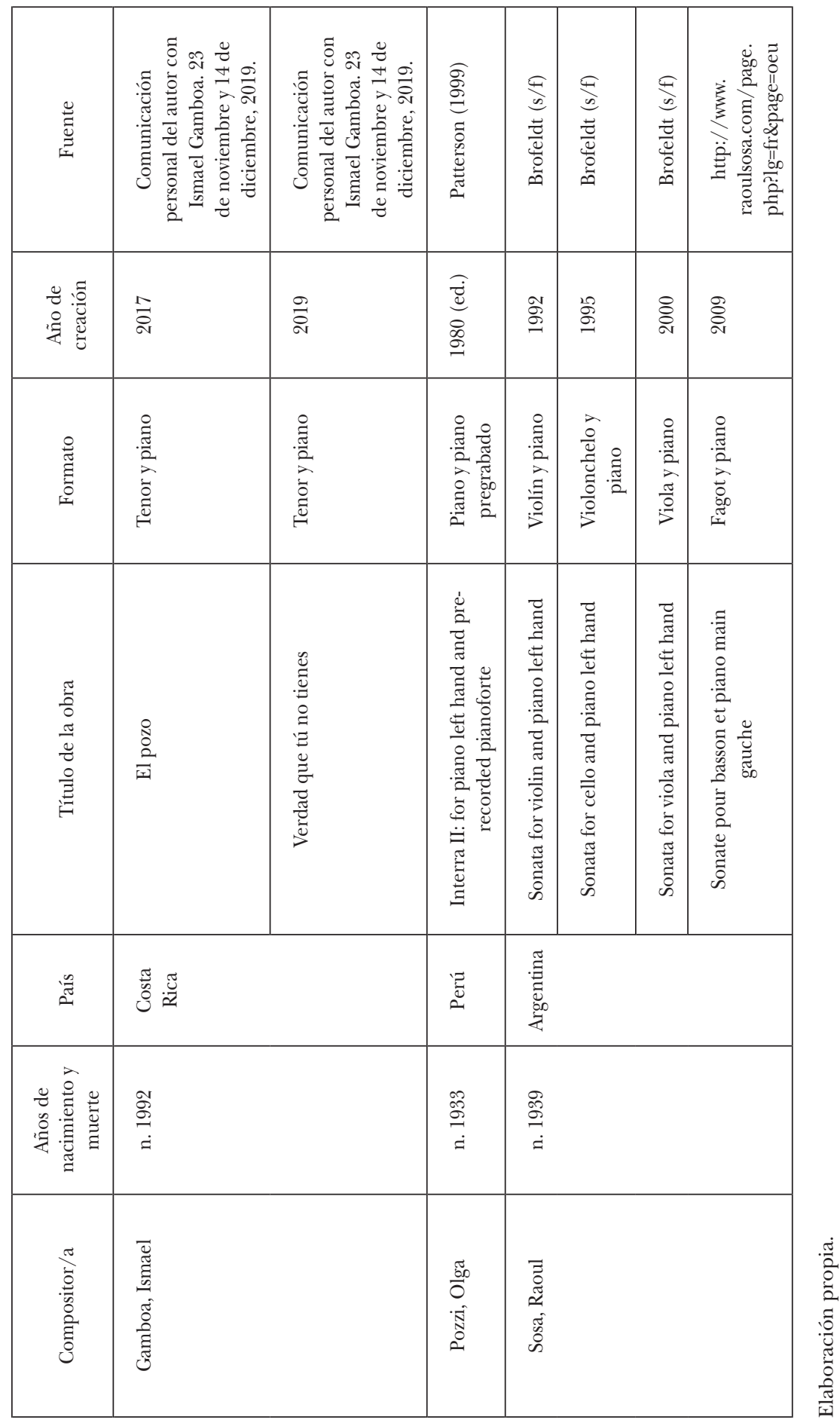




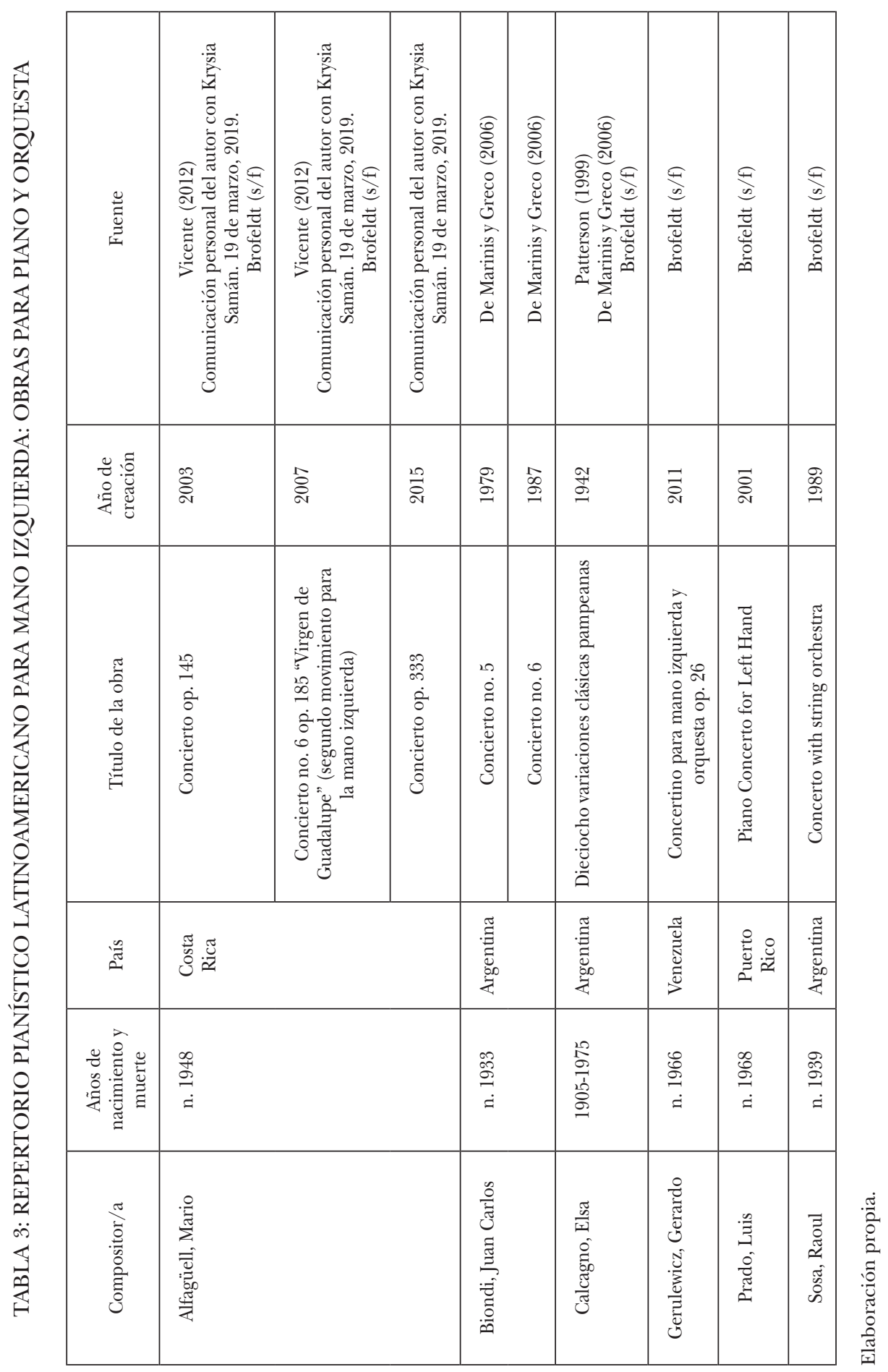




\begin{tabular}{|c|c|c|c|c|c|c|c|c|c|c|c|c|}
\hline 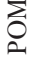 & 0 & 0 & 0 & 0 & 0 & 0 & 0 & - & 0 & 0 & 0 & - \\
\hline$\frac{0}{0}$ & H & 0 & 0 & 0 & $\infty$ & 0 & 0 & 0 & - & 0 & - & $\sigma$ \\
\hline$\dot{0}$ & $H$ & 0 & 0 & 0 & $r$ & 0 & - & 0 & 0 & ov & 0 & $=$ \\
\hline$\dot{\Xi}$ & নి & 8 & H & ov & \&ै & $=$ & N & 0 & - & or & ov & 亏े \\
\hline $\begin{array}{l}\breve{. ~} \\
\text { : }\end{array}$ & $\infty$ & or & - & 0 & $\stackrel{\sim}{*}$ & $\infty$ & ov & 0 & 0 & 0 & 0 & I \\
\hline$\dot{0}$ & จे & $\mathscr{\sim}$ & $\infty$ & ov & $\stackrel{2}{1}$ & $\infty$ & 10 & - & ov & + & $\infty$ & 孚 \\
\hline \pm & 0 & - & 0 & 0 & 0 & 0 & 0 & 0 & 0 & 0 & 0 & N \\
\hline $\begin{array}{l}\bar{x} \\
\text { w } \\
\text { w }\end{array}$ & 0 & \& & - & 0 & 88 & - & - & 0 & - & - & $\infty$ & 음 \\
\hline $\begin{array}{l}\qquad y x \\
\dot{x} \\
\dot{s}\end{array}$ & $\stackrel{2}{\vec{N}}$ & 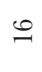 & ov & ov & $\infty$ & $r$ & 0 & - & 0 & $\infty$ & 0 & 8 \\
\hline $\begin{array}{l}\vec{x} \\
\text { w } \\
\text { w }\end{array}$ & 0 & 0 & - & 0 & 0 & 0 & 0 & 0 & - & 0 & 0 & ov \\
\hline$\Sigma$ & - & v & 0 & - & + & - & 0 & - & 0 & 0 & 0 & 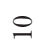 \\
\hline$I$ & H & $\approx$ & $H$ & - & $\sigma$ & N & 10 & 0 & v & ov & - & î \\
\hline है & 10 & $\stackrel{\Omega}{\Omega}$ & 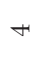 & ov & $\stackrel{2}{\longrightarrow}$ & $\infty$ & 10 & - & ov & or & - & Iु \\
\hline$\dot{0}$ & $\stackrel{\infty}{\sim}$ & 8 & $H$ & ov & 8 & $\exists$ & r & - & ov & + & $m$ & $\overline{\mathbb{N}}$ \\
\hline$\stackrel{0}{\approx}$ & 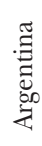 & 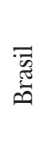 & : & 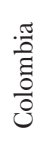 & $\begin{array}{l}\frac{\pi}{2} \\
\frac{\pi}{2} \\
\frac{\pi}{0} \\
0 \\
0\end{array}$ & $\frac{\tilde{E}}{\tilde{J}}$ & 恖 & 莒 & 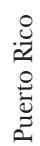 & 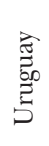 & 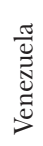 & 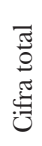 \\
\hline
\end{tabular}

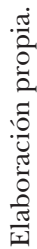




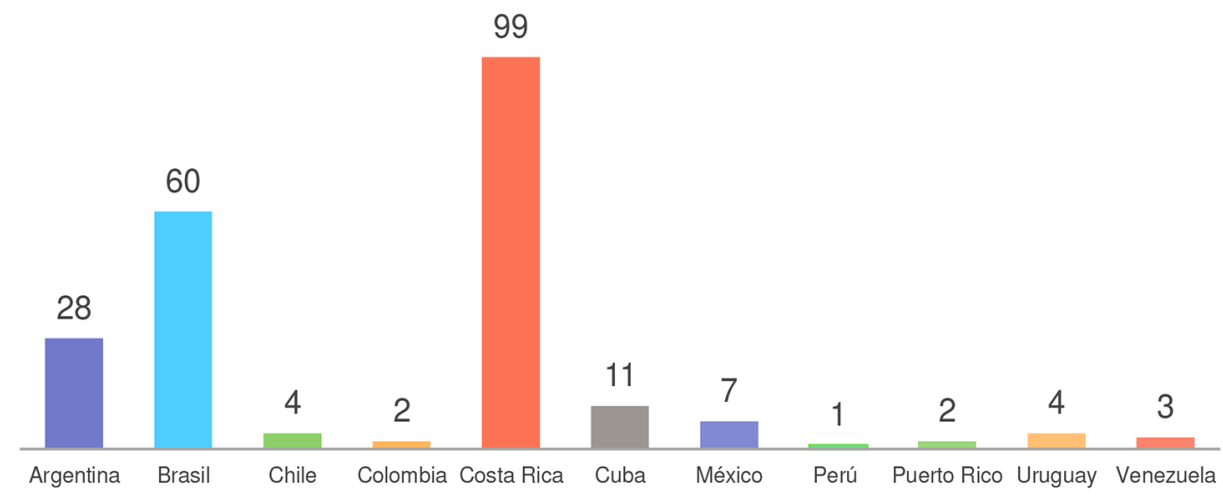

Figura 1: Cantidad de obras por países latinoamericanos (1859-2019)

(Elaboración propia).

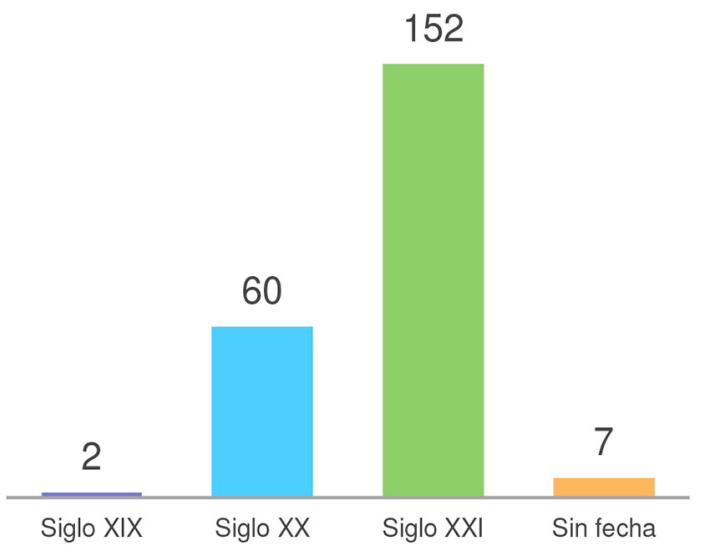

Figura 2: Cantidad de obras latinoamericanas compuestas en cada siglo (1859-2019)

(Elaboración propia).

Asimismo, se reconocen como propias ciento cuarenta y siete obras, al tiempo que setenta y cuatro constituyen transcripciones de partituras originales de compositores europeos. En este caso, se consideró el año en el que se realizó la transcripción, no el año de composición de la partitura original (ver Figura 3). Los datos evidenciaron que 201 de ellas fueron escritas para piano solo, once para diferentes formaciones grupales ${ }^{19}$, nueve requieren acompañamiento orquestal y una para piano y otro medio (ver Figura 4).

19 Antonio Gomezanda compuso su obra para voz y piano, con la posibilidad de ejecutarse también con el piano en solitario; mientras que Mario Alfagüell escribió sus Invenciones, op. 16, para ser interpretadas, indistintamente, solo con la mano izquierda, con la posibilidad de hacerlo también con ambas manos o mediante un grupo vocal/instrumental (utilizando una consonante para la voz). Por ello, se contabilizaron estas partituras en las dos casillas correspondientes: piano solo y grupos. 


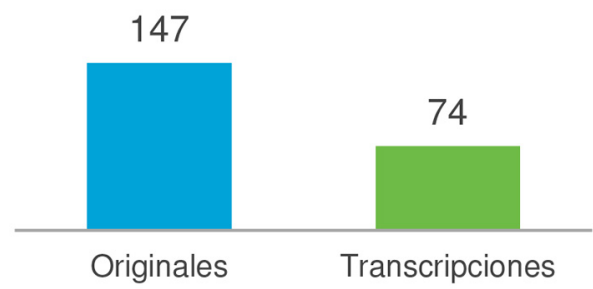

Figura 3: Cantidad de obras originales y transcripciones (1859-2019)

(Elaboración propia).

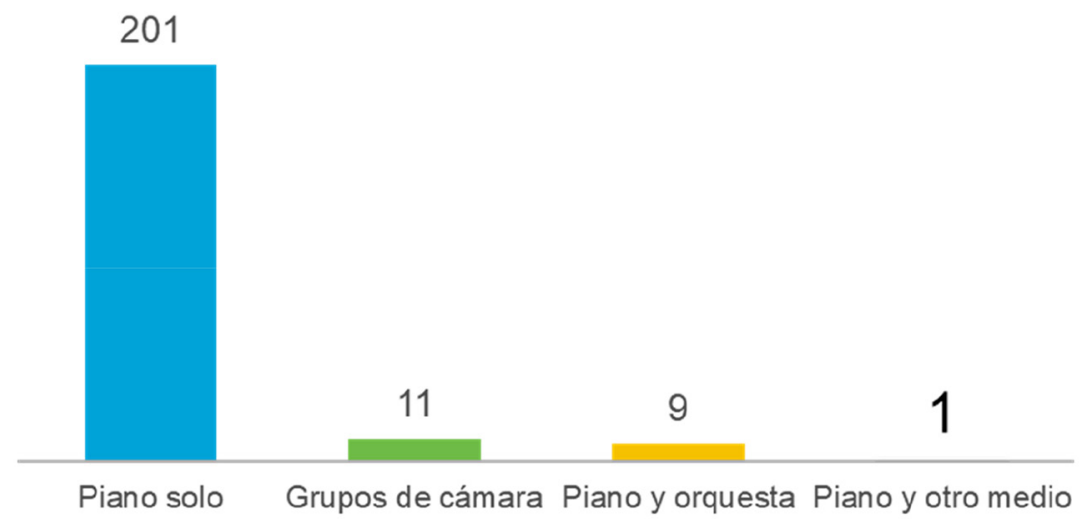

Figura 4: Cantidad de obras según los formatos preferidos por los compositores (1859-2019)

(Elaboración propia).

Próximos estudios acerca de este repertorio podrían incluir información referente al dedicatario, fecha, lugar e intérprete del estreno mundial, edición en partitura, grabación discográfica, publicaciones académicas dedicadas a su estudio y reconocimientos obtenidos por las obras (si los tuviesen). Todos estos datos son de importancia para su debida catalogación. Asimismo, el estudio directo con cada una de las partituras podría devenir en una base de datos bibliográfica más detallada, donde se clasifique este corpus según su función: repertorio didáctico o de concierto, por ejemplo.

Luego de haber comentado los datos contenidos en la Tabla 4, podemos validar la hipótesis planteada al inicio de este artículo, por cuanto Costa Rica es el país latinoamericano con mayor cantidad de obras para mano izquierda en la región. Por ello, el siguiente apartado lo dedicaremos a comentar las condiciones que propiciaron esta voluminosa producción.

\section{APORTE DE COSTA RICA AL REPERTORIO LATINOAMERICANO PARA MANO IZQUIERDA}

Como pudo apreciarse en las Tablas 1 y 2, las primeras obras costarricenses para mano izquierda fueron concebidas por Alfagüell. Sin embargo, el incremento de este repertorio se dio a partir del interés generado por la pianista, compositora y profesora Pilar Aguilar, 
al recibir en su clase de la Universidad de Costa Rica en 2009 a Ismael Gamboa, quien nació sin su brazo derecho. Desde entonces, Aguilar emprendió un arduo camino que le permitiera guiar de la mejor manera posible al estudiante, pues necesitaba contar con obras que no tuvieran un alto grado de dificultad, como las mayormente conocidas del repertorio europeo, ya que debía conformar un programa de trabajo para cada semestre con partituras de diversas épocas (Aguilar 2016, pp. 31-32).

Después de hacer una búsqueda y varias consultas a colegas que se desempeñan en la enseñanza del piano en diferentes partes del mundo, se convenció de la inexistencia de un repertorio que se ajustara a sus necesidades como docente ${ }^{20}$. No obstante, es importante acotar que Wittgenstein dedicó el último volumen de The School For The Left Hand a varias transcripciones de obras originales de otros autores, con diversa procedencia estilística. Estas fueron agrupadas por su autor, teniendo en cuenta el nivel de exigencia de cada partitura, desde las menos complejas hasta otras de mayor dificultad. Además, Patterson destinó el quinto capítulo de su libro a documentar un gran número de antologías pedagógicas para la ejecución del piano con una sola mano (Patterson 1999, pp. 259-282) ${ }^{21}$.

Aguilar se dio a la tarea de hacer versiones de algunas obras del repertorio pedagógico para ser ejecutadas únicamente con la mano izquierda (Aguilar 2016: 32), como se pudo apreciar en la Tabla 1. Pero también asumió el reto de concebir obras originales para esta mano sola, con el propósito de que su estudiante abordara otras dificultades técnicoartísticas. Este ingente trabajo quedó recogido en el libro Metodología para la enseñanza del piano para solo la mano izquierda (2016), publicado por el Centro Nacional de la Música. En él encontramos las partituras agrupadas por períodos musicales y niveles de dificultad, de manera que los docentes y estudiantes interesados en abordar un repertorio con estas características lo puedan hacer, teniendo en cuenta varios grados de exigencia para su ejecución. Como complemento a ello, Aguilar dejó por escrito muchos ejercicios de calentamiento que los pianistas deben realizar previo al trabajo directo con las obras.

A modo de prólogo del libro, María Isabel Carvajal asegura que:

Aunque la pianista y compositora Pilar Aguilar Muñoz ha realizado un número considerable de creaciones musicales, ninguna a mi parecer posee tanta importancia como esta ya que comprende un aporte especializado en el desarrollo básico de ejercicios para la mano izquierda, además de arreglos y transcripciones de obras musicales para piano, tanto del repertorio universal como de su autoría. Asimismo extendió su propuesta a otros compositores costarricenses con la finalidad de incluir sus obras para solo la mano izquierda como parte del método (Aguilar 2016: 29).

Precisamente, otro de los aportes de este texto estriba en la inclusión de partituras de varios compositores costarricenses, las que fueron comisionadas por la autora, en aras de contar con un corpus original más amplio, hecho en su país. A esta iniciativa respondieron doce creadores: Alfagüell, Vargas, Alejandro Cardona (n. 1959), Akiana Molina (n. 1963) ${ }^{22}$, Eddie Mora (n. 1965), Marvin Camacho (n. 1966), Sandra Duarte

20 Según Aguilar, solamente pudo obtener el libro Piano Music for One Hand (G. Schirmer, 1972), un compendio de estudios, ejercicios y piezas seleccionadas por su editor Raymond Lewenthal (Aguilar 2016, pp. 31-32). Por su parte, Gamboa asegura que tuvieron conocimiento del libro Piano Music for One Hand (1999) de Edel, aunque no menciona al autor (Aguilar 2016: 38).

21 Una propuesta metodológica más reciente puede encontrarse en la tesis doctoral de Lee (2017, pp. 29-60).

22 El nombre que aparece en Aguilar (2016) es Patricia Molina, pero la compositora ha optado por cambiarlo legalmente por Akiana Molina (Comunicación personal con el autor, 2 de marzo, 2019). 
(n. 1968), Carlos Escalante (n. 1968), Otto Castro (n. 1972), Mora-Jiménez y el propio Ismael Gamboa; según consta en la Tabla 1. No todas las obras escritas por Alfagüell hasta el 2016 fueron publicadas en el libro de Aguilar, pues se trata de un conjunto voluminoso que valdría la pena estudiar y difundir de forma independiente. Además, hasta el momento es el único costarricense en escribir conciertos para piano (con la mano izquierda) y orquesta.

Al tratarse de un libro con fines didácticos, las partituras comisionadas por Aguilar no demandan de los intérpretes grandes retos virtuosísticos. No obstante, algunas de ellas son más "pianísticas" que otras, entendiendo por este término que se adaptan mejor a los diseños y posibilidades reales para su ejecución en el instrumento. El autor de este artículo ha tenido la posibilidad de estrenar algunas de esas obras, incluso, antes de que fuese publicado el libro, a saber: Canto Triste (2012) y Elucubraciones (2012) de Aguilar, Preludio y Habanera de Camacho (2014) ${ }^{23}$, Troika (2014) de Mora ${ }^{24}$ y Mujeres de viento (2014) de Escalante. A partir de este acercamiento interpretativo, que transcurrió entre el 2014 y 2017 y la observación de las partituras restantes de autores costarricenses, pudo llegarse a la conclusión de que, aunque algunas no presentan grandes dificultades de ejecución, sí demandan la expertise de un pianista profesional para solventar algunos aspectos vinculantes a la estructura, digitación, pedalización y creatividad interpretativa.

Las inspiraciones musicales y extramusicales tienen diversa procedencia. Pueden observarse en las partituras, bien a partir de sus títulos, anotaciones de los creadores o elementos constitutivos en el pentagrama. Por ejemplo, Alfagüell materializa su imaginario sonoro tomando como herramienta el aleatorismo y utiliza como materia prima un canto aborigen para concebir sus 46 Estudios (sobre un canto indígena Bribri de Costa Rica), op. 186 (2007). Por su parte, Cardona toma como fuente de inspiración un par de fragmentos del cuento El canto de los cronopios (1962) de Julio Cortázar (1914-1984), uno para cada canto que compone su obra pianística. Precisamente, la partitura fue concebida y dedicada al escritor argentino el día de su centenario. La obra de Castro lleva por nombre una palabra de la lengua náhuatl, Kiauitl (2014), cuyo significado es lluvia. Según su autor, con ella pretende realizar una "invocación al clima y al alto porcentaje de humedad de Costa Rica” (Aguilar 2016: 371).

Por otro lado, Mora se inspira en sus años de estudio en Rusia para denominar y desarrollar las tres piezas que componen su ciclo Troika. En ellas recrea diferentes momentos relacionados con ese país: Sputnik, "lo incierto del cosmos (inspirado en una imagen de la época)"; Stal, "la tragedia y los gritos de terror del 'acero'”; y Perestroika en $D$, “una alegría (con unas pocas disonancias) de lo que fue esa inolvidable época [para el compositor]" (Chatski 2016: párr. 10). En la obra de Camacho nos encontramos con otro acercamiento suyo a la habanera, ritmo cubano-español que ha utilizado como insumo en diversas partituras: Tres Quijotadas de un Hidalgo para piano (2009), Disparate y Locura para saxofón y piano (2010) y Obertura y Habanera para banda (2013).

Escalante, por su parte, concibió Mujeres de viento a partir de un material suyo para la música incidental de una coreografía de Denise Fujiwara, mientras que Vargas tomó el ritmo del pasillo, muy popular en la música de salón de principios del siglo XX costarricense, para escribir su obra Febrero op. 369. El resto de las partituras, donde se incluyen las de Aguilar, Molina, Duarte, Mora-Jiménez y Gamboa, contienen títulos descriptivos que

23 Grabada en el disco Piano Ritual (2016).

24 Grabada en el disco Plegaria (2016). 
sugieren la intención de sus creadores, información válida para abordar la interpretación de las mismas.

A petición de Aguilar, la mayoría de estas obras tienen un carácter eminentemente pedagógico, ya que su libro constituye una guía metodológica para la enseñanza del piano con la mano izquierda. De ahí que se puede apreciar una variedad amplia que se extiende desde el ciclo de piezas de Molina, el Intermezzo (2013) de Gamboa y algunos de los Cromatismos (2012-2016) y Pentatónicas (2012-2016) de Aguilar (dirigidas a estudiantes iniciales e intermedios); hasta obras de mayor dificultad, no solo por los retos que demandan a nivel de ejecución, sino también por el uso del lenguaje contemporáneo, como es el caso de Alfagüell, Cardona, Mora, Camacho, Duarte, Castro y Mora-Jiménez. Lo interesante de este compendio de partituras puede valorarse, además, por la diversidad de estéticas, a pesar de pertenecer a creadores de un mismo país y generaciones que conviven en igual período.

\section{CONCLUSIONES}

El repertorio escrito hasta el momento para la mano izquierda es tan vasto que los pianistas que decidan adentrarse en él tendrán material suficiente para elaborar sus propuestas artísticas, aun cuando no se vean obligados a abordarlo por alguna condición física. A pesar de ello, no contamos con la cantidad suficiente de textos de síntesis que contribuyan a documentarlo hasta nuestros días y estudiar desde diferentes perspectivas las posibilidades que ofrece, tanto para el desempeño profesional como desde sus componentes formativos.

Las fuentes consultadas fueron de gran importancia para la documentación del repertorio latinoamericano aquí expuesto. No obstante, urge la publicación de un texto de mayor volumen, que concentre no solo el corpus, sino también detalles más específicos, como la existencia de ediciones en partituras, datos del estreno y grabación sonora de las obras, así como artículos y libros que han basado sus investigaciones en ellas, entre otros aspectos de interés.

Las tablas confeccionadas durante esta investigación deben considerarse solo como un primer intento para documentar el corpus estudiado, con el deseo de que sus registros aumenten en el futuro, gracias al interés de otros colegas. No obstante, queremos ponderar el hecho de que Costa Rica sea el país que más ha aportado a la literatura latinoamericana para la mano izquierda. Sin dudas, la iniciativa de la profesora Aguilar impulsó la creación de obras originales con estas características, pero también incrementó la cantidad de transcripciones didácticas a partir del repertorio pedagógico para ambas manos. Al ser Costa Rica un país pequeño, con una historia relativamente reciente en el campo de la música académica y, más específicamente, en la ejecución del piano a nivel internacional, este aporte lo visibiliza ante la región latinoamericana.

Varios son los colegas que debaten continuamente acerca de ofrecer una formación musical diseñada de manera ascendente desde las edades tempranas, a partir del repertorio creado por nuestros compositores, sin tener que acudir insistentemente a las obras que nos ha legado la historia musical europea. Si bien el piano es un instrumento heredado de la cultura occidental, es evidente que en Latinoamérica existe una literatura vasta, aún por descubrir. Con ello pretendemos volver la mirada hacia nosotros mismos, a hurgar en esos sonidos propios y a replantearnos la dependencia exclusiva del repertorio canónico europeo para la formación de nuestros estudiantes y su posterior desempeño profesional. 
El debate sigue abierto, pero consideramos que como región aportamos más defendiendo nuestra diversidad cultural, conociendo y difundiendo más lo que producimos.

\section{BIBLIOGRAFÍA}

Acebo, Waldo

2017 Conciertos para la mano izquierda. cubaencuentro.com. Disponible en: https:/ /www.cubaencuentro.com/cultura/articulos/conciertos-para-la-mano-izquierda-328783 [acceso: 26 de mayo de 2019].

Aguilar, Pilar

2016 Metodología para la enseñanza del piano para solo la mano izquierda. San José: Centro Nacional de la Música.

BrofELDT, HaNS

s/f Piano Music for the Left Hand Alone. Disponible en http://www.left-hand-brofeldt.dk/index. htm [acceso: 1 de junio de 2019].

Carrascosa, Flavia

2016 "Preludios de mujeres: abordaje comparativo del empleo de la forma en la obra de Elsa Calcagno y Lía Cimaglia Espinosa”. Semana de la Música y la Musicología: El piano. Historia, didáctica e interpretación. Disponible en: http://bibliotecadigital.uca.edu.ar/repositorio/ ponencias/preludios-mujeres-abordaje-forma.pdf [acceso: 1 de marzo de 2019].

Castañeda, Mireya

2015 Cecilio Tieles y las voces de los más actuales compositores cubanos. Granma. Disponible en: http:/ / www.granma.cu/cultura/2015-12-04/cecilio-tieles-y-las-voces-de-los-mas-actuales-compositores-cubanos-01-02-2016-09-02-35 [acceso: 23 de febrero de 2019.

Chatski, Ekaterina

2012 "Rutas para explorar los elementos estilísticos del lenguaje musical de un compositor" en Música académica costarricense. Del presente al pasado cercano. Ekaterina Chatski, María Clara Vargas, y Tania Vicente. San José: Editorial de la Universidad de Costa Rica, pp. 59-268.

2016 "Plegaria - Reseña”. Reseña del disco Plegaria del compositor Eddie Mora. Disponible en: http://eddiemora.com/es/plegaria-2/ [acceso: 1 de marzo de 2019].

De Araujo, Helder

2009 "A composição brasileira de piano para a mão esquerda". Tesis de Doctorado en la Universidade de São Paulo, Brasil.

De Elía, Oscar y Juan Trepiana

2009 Método Progresivo de Piano Tango, Vol. 1. Buenos Aires: Altavoz Editorial.

De La Hoz, Pedro

2006 ¿En el piano? Valera imprescindible. Granma. Disponible en: http://www.granma.cu/gran$\mathrm{mad} / 2006 / 03 / 21 /$ cultura/artic05.html [acceso: 5 de abril de 2019].

De Marinis, Dora y María Emilia Greco

2006 "Obras para piano y orquesta en la Argentina. Un aporte preliminar al estudio del género en nuestro país", Huellas, 5, pp. 17-40.

EDEL, THEODORE

1994 Piano Music for One Hand. Bloomington: Indiana University Press.

HirokaWa, KaORU

2019 Laboratorio de Música Latinoamericana para Piano. Disponible en: http:/ / pianolatinoamerica. org/index_esp.html [acceso: 1 de junio de 2019]. 
Howe, Blake

2010 "Paul Wittgenstein and the Performance Of Disability". The Journal of Musicology, XXVII/2 (primavera), pp. 135-180, doi: https://doi.org/10.1525/jm.2010.27.2.135

Kuhn, Laura y McIntire Dennis

2001 "Biografía de Alfonso Montecino" en Baker's BiographicalDictionary of Musicians. Disponible en: https://www.encyclopedia.com/arts/dictionaries-thesauruses-pictures-and-press-releases/ montecino-alfonso [acceso: 31 de mayo de 2019].

LEE, MinjI

2017 "A Pedagogical Approach to Teaching Left-Handed Piano Repertoire". Tesis de Doctorado en Texas Tech University.

LERNER, NEIL

2006 "The Horrors of One-Handed Pianism: Music and Disability in The Beast with Five Fingers", Sounding Off: Theorizing Disability in Music. Neil Lerner y Joseph Straus (editores). Nueva York: Routledge Taylor \& Francis Group, pp. 75-89.

LEWENTHAL, RAYMOND

1972 Piano Music for One Hand. Nueva York: G. Schirmer.

McRoberts, TERry

2000 "One Handed: A Guide to Piano Music for One Hand by Donald L. Patterson (review)", College Music Symposium, 40, pp. 170-171.

Moro, Daniel

2007 "La literatura pianística para la mano izquierda sola", Resonancias, Revista del Conservatorio Superior de Música del Principado de Asturias, II/3, pp. 28-39.

Nieto, Albert

1991 "Piano: música para la mano izquierda". Introducción general y notas al programa del ciclo de conciertos. Fundación Juan March, pp. 12-31.

Patterson, Donald

1999 One Handed: A Guide to Piano Music for One Hand. Westport, Connecticut: Greenwood Press.

Rocca, Mariano

2017 "Biografía de Horacio López de la Rosa" en Compositores E̊ Intérpretes. Disponible en: http:/ / ciweb.com.ar/Lopez_de_la_Rosa/[acceso: 31 de mayo de 2019].

SERracanta, Francesc

2019 "Obras mexicanas" en Historia de la Sinfonía: un viaje por la historia a través de la música. Disponible en: http:/ /www.historiadelasinfonia.es/naciones/la-sinfonia-en-mexico/obrasmexicanas/ [acceso: 31 de mayo de 2019].

TORO, ANGÉlica

2018 Nuevas piezas colombianas para la iniciación al piano. Medellín: Universidad EAFIT.

VARgas, María Clara

2004 De las fanfarrias a las salas de concierto: música en Costa Rica (1840-1940). San José: Editorial de la Universidad de Costa Rica.

2012 "Un escenario caleidoscópico: música en Costa Rica (1940-2010)", Música académica costarricense. Del presente al pasado cercano. Ekaterina Chatski, María Clara Vargas, y Tania Vicente (autoras). San José: Editorial de la Universidad de Costa Rica, pp. 17-58.

VICENTE, TANIA

2012 "Biografías de compositores costarricenses contemporáneos" en Música académica costarricense. Del presente al pasado cercano. Ekaterina Chatski, María Clara Vargas, y Tania Vicente (autoras). San José: Editorial de la Universidad de Costa Rica, pp. 269-334. 


\section{WiLEy, AdRIENNE}

2000 "One-Handed: A Guide to Piano Music for One Hand (review)", Notes, LVII/2, pp. 377-378. doi: https://doi.org/10.1353/not.2000.0114

\section{Discos compactos}

\section{Camacho, Marvin}

2016 Piano Ritual. Disponible en: https://music.apple.com/mx/album/piano-ritual/1162251164 [acceso: 23 de marzo de 2019].

MORA, EdDIE

2016 Plegaria. Disponible en: http://eddiemora.com/es/plegaria-2/ [acceso: 23 de marzo de 2019]. 